Esta revista forma parte del acervo de la Biblioteca Jurídica Virtual del Instituto de Investigaciones Jurídicas de la UNAM

\title{
La idea de los bienes comunes en el sistema internacional: ¿renacimiento o extinción?
}

\section{The Idea of Common Goods in the International System. Revival or Extinction?}

\section{María Cecilia Añaños Meza*}

SUMARIO: I. Introducción. II. Los bienes comunes como propuesta de acción colectiva institucional. III. El régimen jurídico moderno de los bienes comunes: patrimonio común de la humanidad. IV. Los bienes comunes en la visión de Francisco de Vitoria. V. Conclusión. VI. Bibliografía.

* Doctora en Derechos Fundamentales (Madrid, España), magister legum en Derecho Internacional Público y Derecho Público (Kiel, Alemania), licenciada en Derecho, docente y traductora.ceciliaan@web.de. 
RESUMEN: La idea de los bienes comunes ha experimentado en los últimos años un renacimiento gracias a las investigaciones realizadas principalmente en las ciencias económicas, y a su presencia en creaciones intelectuales. Mas su existencia en el sistema internacional sigue siendo exigua y controvertida, sobre todo tratándose de espacios o recursos comunes globales que actualmente parecen someterse a las tendencias globales de privatización y comercialización. El presente trabajo se ocupará de esclarecer en qué medida este sistema internacional reconoce la idea de los bienes comunes en los recursos globales y si cabe referirse a su renacimiento a este nivel.

Palabras claves: Bienes comunes, recursos de uso común, res communes, bienes comunes globales, commons, Ostrom, tragedia de los comunes, patrimonio común de la humanidad, fondos marinos, espacio ultraterrestre, cuerpos celestes, Antártida, Francisco de Vitoria, sociedad y comunicación natural, res nullius, ocupación, nuevo mundo.

ABSTRACT: The idea of the common goods has experienced a revival in the last years, due especially to the studies made in the economic sciences and to the presence of intelectual creations. However, its existence in the international system is still being exiguous and controversial, mainly with reference to the global common spaces or resources, which seem to be exposed to the global trends of privatization and commercialization. This paper will be concerned with the clarification of the question, to what extent this international system admits the idea of the common goods in global resources, and if it is suitable to speak of their revival at this level.

Descriptors: Common goods, Common pool resources, res communes, Global common goods, commons, Ostrom, tragedy of the common, common heritage of mankind, seabed, outer space, heavenly body, Antarctica, Francisco de Vitoria, society and natural communication, res nullius, occupation, New World.

RÉSUMÉ: L'idée des biens communs a expérimenté dans les dernières années une renaissance grâce aux recherches réalisées dans les sciences économiques, et à leur présence dans les créations intellectuelles. Toutefois, leur existence dans le système international continue en train d'être exiguë et controversé, surtout en concernant des espaces ou ressources communs globales qui actuellement semblent se soumettre aux tendances globales de privatisation et commercialisation. Cet article s'occupera d'élucider dans quelle mesure ce système international reconnaît l'idée des biens communs dans les ressources globales et si est possible parler d'une renaissance à ce niveau.

Mots-clés: Biens communs, ressources d'usage commun, res communes, biens communs globales, commons, Ostrom, tragédie des communs, patrimoine commun de l'humanité, fonds marins, espace cosmique, corps célestes, Antarctique, François de Victoria, société et communication naturelle, res nullius, occupation, Nouveau Monde. 


\section{INTRODUCCIÓN}

En tiempos en los que, pese a los resquebrajamientos inmanentes del sistema capitalista, la sociedad internacional sigue experimentando aún la plena vigencia del capitalismo globalizado, caracterizado por la maximización del proceso de liberación económica con el resultado de la privatización de todo bien económicamente explotable, y la multiplicación, concentración y acumulación del capital, se hace difícil concebir la idea antagónica de los bienes comunes, que ha estado presente desde la Antigüedad, pero que parece haber quedado relegada en un rincón empolvado por el tiempo, fuera del alcance de nuestra percepción y realidad habitual. Vale la pena, entonces, formular la pregunta de si el sistema internacional del presente conoce o acepta su existencia, y de ser la respuesta positiva, cómo y en qué extensión lo hace.

A primera vista esta pregunta se responde de forma afirmativa. Los bienes comunes siguen existiendo como idea y realidad en un mundo "liberalizado" e individualizado como el presente, aunque aún de forma muy modesta o exigua. El sistema internacional conoce de su existencia, e incluso cuenta con un régimen rudimentario para un número más limitado de ellos. En el primer caso, es visible tanto el renacimiento de "bienes comunes modernos" o commons de naturaleza intangible, como la larga y constante investigación sobre commons tangibles en los últimos decenios. En el segundo caso, existe un régimen jurídico internacional sobre determinados bienes que han sido declarados por la sociedad internacional como "comunes", y que son conocidos en su denominación moderna de "patrimonio común de la humanidad".

Esta presencia remodernizada de los bienes comunes, que es de gran relevancia como forma alternativa de organización económico-social más allá de los parámetros del mercado y del Estado, y que es bien recibida por resaltar principios casi perdidos como los de sociabilidad, cooperación, reciprocidad, equidad, etcétera, experimentó su reaparición en el siglo XVI por el ilustre iusinternacionalista Francisco de Vitoria, quien la aplicó como parte sustancial de justificación del dominio español en el nuevo mundo. 
El presente trabajo hace un acercamiento a esta idea, concentrándose en los recursos tangibles. De manera expositiva arrojará luces sobre sus tres diferentes manifestaciones o coordenadas: una en el contexto actual que incluye una propuesta o programa de organización social desde la economía política; otra de carácter jurídico que nos informará sobre el estado normativo actual que rige estos recursos, y una tercera, desde la historia del pensamiento, en la que se conocerá el empleo de esta idea en Francisco de Vitoria al caso de la conquista española en el nuevo mundo. Coordenadas que a primera vista no parecen tener relación alguna entre sí por haberse desarrollado independientemente una de otra, sin embargo, tienen en común la misma idea: los bienes comunes, y contribuyen de diferente forma a ella. Por contener cada una de ellas materias amplísimas, que sirven de objeto de estudios especializados, se les tratará sólo a grosso modo, teniendo como punto de referencia constante el sistema internacional.

\section{LOS BIENES COMUNES COMO PROPUESTA DE ACCIÓN COLECTIVA INSTITUCIONAL}

La existencia de la idea moderna de los bienes comunes no es difícil de determinar. Después de haberse borrado sus huellas hacia el siglo XIX, aparece en los años sesenta del siglo XX en un estudio sobre la "acción colectiva” y "bienes colectivos" del economista Mancur Olson, ${ }^{1}$ que marca el inicio de un largo debate académico y de investigación científica sobre ellos hasta el presente. Pocos años después de publicado este estudio, aparece otro trabajo que arroja un escrutinio negativo de los bienes comunes, al verlos como modelo no recomendable para solucionar los problemas de agotabilidad o depredación de recursos agotables o consumibles que están a libre disposición en el planeta, ello debido a

1 Olson, M., The Logic of Collective Action, Cambridge, Harvard University Press, 1965; en castellano aparece bajo el nombre de La lógica de la acción colectiva: bienes públicos y la teoría de grupos, México, Limusa, 1992. Su modelo de acción colectiva se basa en incentivos a individuos racionales, orientados por el interés propio y la maximización de la utilidad, para que trabajen en interés colectivo. 
su fracaso irremediable a causa de la naturaleza racional del hombre que tiende a su uso excesivo o abuso para procurar su propia maximización de la utilidad. Asunción ésta que fue conocida con la famosa frase de la "tragedia de los comunes", cuyo autor, el biólogo Garrett Hardin, hizo pública en 1968 en su artículo que lleva el mismo título, ${ }^{2}$ y trajo la consecuencia desfavorable de catapultar el descrédito de estos bienes, al ser comúnmente referidos en los debates académicos para sostener su inviabilidad y dar paso a recetas de solución basadas en las leyes del mercado o en la intervención del Estado.

Sin embargo, esta tesis pudo ser refutada por investigaciones económicas posteriores que reinvidicaron el valor de los bienes comunes como forma beneficiosa de organización económico-social. Mas su revalorización actual se debe sobre todo a Elinor Ostrom, quien ha contribuido decisivamente al desarrollo de una nueva ciencia de los bienes comunes. Gracias a su investigación, basada en datos empíricos que demuestran su éxito en diferentes contextos culturales, conocemos que ellos pueden ser manejados sosteniblemente. ${ }^{3}$ Es más, la misma autora asume que un régimen de bienes comunes puede ser incluso más efectivo para sus miembros que el de propiedad privada o pública, ${ }^{4}$ haciendo visible con ello la insostenibilidad de teorías que asumían llanamente su fracaso o ineficiencia, como la de Hardin. ${ }^{5}$ De allí desarrolló una teoría, a la que denomina "economía institucional de los bienes comunes" o "teoría de la acción colectiva institucional basada en normas", en la que determina las condiciones que deben existir para su organización y

2 Hardin, G., "The Tragedy of the Commons", Science, New Series, vol. 162, núm. 3859, 1968, pp. 1243-1248, advirtió que en el uso de un bien libre los maximizadores de la utilidad privatizan la ganancia pero socializan las pérdidas, por ello, la libertad en los commons arruinaría a todos; problema también conocido como el "dilema del prisionero" en la teoría de juegos, cuya solución, la daría el Estado o el mercado; a esto véase Ostrom, E., El gobierno de los bienes comunes, México, Fondo de Cultura Económica, 2000, pp. 28 y ss.

Ostrom, E., The Logic..., cit., p. 26. Precisamente por su valiosa contribución al concepto de los bienes comunes se le otorgó el Premio Nobel de Economía de 2009.

4 Entrevista Adam Smith, jefe editor de Nobelprize.org, http://www.nobelprize.org/nobel_ prizes/economics/laureates/2009/ostrom-telephone.html (1 de mayo de 2013).

Se dirige contra 3 modelos de la teoría de la acción colectiva: la "tragedia de comunes" de Hardin, el dilema del prisionero y la lógica de la acción colectiva de Olson, que advierten sobre el problema del polizón o gorrón; Ostrom lo tiene en cuenta, pero cree que los individuos pueden superarlo, Ostrom, E., The Logic..., cit., pp. 26 y ss., 32. 
Esta revista forma parte del acervo de la Biblioteca Jurídica Virtual del Instituto de Investigaciones Jurídicas de la UNAM

manejo exitoso; es decir, su uso efectivo, beneficioso para todos y que no implique su destrucción o menoscabo. En lo que sigue, nos acercaremos a las ideas de Ostrom puntualizando los conceptos, elementos y principios relevantes de los bienes comunes.

\section{La idea moderna de los bienes comunes}

Los bienes comunes o commons son formas específicas de acuerdos sociales para el uso colectivo, sostenible y justo de recursos comunes. ${ }^{6}$ Se les entiende también como regímenes autorregulados, cuyo acceso, uso y derechos de participación en ellos están regidos por reglas determinadas por la comunidad misma de estos bienes. Importante es resaltar la tridimensionalidad de sus componentes estructurales: el material, el social y el regulativo; radicando el primero en los bienes mismos; el segundo en los individuos, y el tercero en las reglas sobre las relaciones de éstos entre sí y con el bien común. ${ }^{7}$

Tampoco puede tenerse una comprensión cabal de los bienes comunes sin conocer sus formas existentes, que siguen la división clásica romana de los bienes materiales e inmateriales. Los primeros, que son llamados recursos de uso común (RUC), tienen la característica de ser agotables, rivales y escaseables, ${ }^{8}$ así como de llevar consigo altos costos de exclusión, están sujetos a reglas que contienen un manejo responsable de ellos para evitar su agotamiento y/o depredación, y de reglas

6 "Spezifische Formen sozialer Übereinkünfte zur kollektiven, nachhaltigen und fairen Nutzung von Gemeinressourcen", Helfrich/Stein, "Was sind Gemeingüter?", APuZ 28-30/2011, 9-15, p. 9. Existe una literatura abundante sobre los bienes comunes, principalmente desde la ciencia económica; baste refererirnos a Ostrom, E. et al. (eds.), The Drama of the Commons, Washington DC, National Academy Press, 2002, ilustrativo del estado de la discusión actual.

${ }^{7}$ Helfrich, S. et al., Gemeingüter -Wohlstand durch Teilen, Berlín, Report Heinrich Böll Stiftung, pp. 11 y ss.

8 En el lenguaje de Ostrom: "recursos de uso comun" (RUC) son "un sistema de recursos naturales o hechos por el hombre, que es bastante grande como para hacer costoso (pero no imposible) excluir a potenciales usuarios de su uso”, Ostrom, op. cit., p. 66. Sus atributos definitorios son la substracción o rivalidad y la no exclusividad o exclusión costosa. Entre ellos estudió las pesquerías, pastizales, sistemas de irrigación, bosques comunales, lagos y cuencas subterráneas a nivel local, véase Ostrom, The Logic..., cit., p. 58. 
Esta revista forma parte del acervo de la Biblioteca Jurídica Virtual del Instituto de Investigaciones Jurídicas de la UNAM

justas de un acceso limitado. Gran parte de ellos se encuentra en la naturaleza, como la atmósfera, el aire, el agua, los campos, los bosques, los lagos, las semillas, las materias primas, la diversidad bio-genética, la tierra, los océanos, el espacio sideral, los cuerpos celestes, los fondos marinos, etcétera, y otra se encuentra en obras producidas por el hombre, como carreteras, puentes, canales, etcétera. ${ }^{9}$ Los segundos, que son intangibles o creaciones intelectuales libres, como la Internet, el conocimiento, la ciencia, la cultura, la información, las ideas, el software libre o código abierto, ${ }^{10}$ el hardware libre, la enciclopedia libre Wikipedia, el régimen de open access en la ciencia, ${ }^{11}$ etcétera, no tienen en sí el problema de escaseamiento, pues no se desgastan con el consumo ni su uso perjudica el uso de otro, es decir, no son rivales; son llamados bienes comunes "modernos" porque gozan de vitalidad en la sociedad internacional aún siendo su número tan exiguo en una economía mundial liberal que estimula el beneficio individual. ${ }^{12}$ Dentro de esta gran variedad de commons se encuentran, por último, los bienes

9 Wiskow diferencia dos grupos de RUC según los costos de exclusión de su uso a potenciales usuarios: los de acceso libre (open access resource) y los de acceso limitado. Los primeros no pertenecen a nadie y son de uso de todos, aunque este sistema genera el dilema del prisionero si su uso no está regulado. Los segundos son de posesión común (common-property resource), proveen a sus miembros de beneficios y facilidades basados en costos compartidos y su acceso exclusivo no genera el dilema del prisionero por haber un grupo definido de usuarios o adquirientes, Wiskow, J.-H., Zur Verfassung der Meere, Köln, Institut der Universität zu Köln, 2002, p. 25; en este autor los factores que permiten superar el dilema del prisionero son: un grupo relativamente pequeño y estable, una misma afectabilidad, un alto grado de homogeneidad en el grupo, bajos costos de transacción derivables de un amplio capital social, un discontraste bajo o alta valoración de ingresos futuros y previsión de posibles daños, ibidem, p. 55.

10 Visible en el sistema de GNU/Linux del movimiento del software libre o en la organización internacional de Creative Commons con sus modelos de licencia para uso general. A esto véase Benkler, Y., TheWealth of Networks, Yale University Press, 2006, accesible bajo licencia de Creative Commons.

${ }^{11}$ Declaración de Berlín de 2003 (Berlin Declaration on Open Access to Knowledge in the Sciences and Humanities) http: / / www.zim.mpg.de/openaccess-berlin/berlin_declaration.pdf (9 de marzo de 2012). Para un estudio más profundo de estos bienes y los problemas de su escaseamiento artificial véase Boyle, J., "The Second Enclosure Movement and the Construction of the Public Domain”, Law and Contemporary Problems, vol. 66, 33, 2003 http: / /scholarship.law.duke.edu/cgi/ viewcontent.cgi? article $=1273$ \& context $=1 c p(9$ de septiembre de 2012).

12 Estos commons no deben confundirse con servicios de acceso abierto a usuarios como Facebook Inc. o Google Inc., que son empresas privadas globales con claros fines de lucro. 
Esta revista forma parte del acervo de la Biblioteca Jurídica Virtual del Instituto de Investigaciones Jurídicas de la UNAM

comunes globales o "recursos de acceso abierto" como los fondos marinos, el alta mar, la atmósfera, la Antártida, el espacio ultraterrestre, el espacio cibernético, que llevan tal nombre por estar fuera del alcance de las jurisdicciones nacionales de los Estados, siendo todos ellos, a excepción del espacio cibernético, espacios que albergan recursos naturales de vital importancia para la subsistencia del hombre y/o de gran importancia económica, a los cuales nos referiremos en este trabajo.

\section{Condiciones y principios de los bienes comunes}

No existen bienes comunes sin un acuerdo previo entre los usuarios o propietarios en el cual reglamentan su adquisición, uso y distribución para beneficio de todos y de cada uno de ellos. Un elemento esencial de ellos es pues, la existencia de un régimen autónomo de regulación, que es un proceso social complejo con exigencias propias y formas variadas que dependen sobre todo de la naturaleza del recurso, pero también de la constitución de la comunidad de usuarios y de sus instituciones, ${ }^{13}$ los mismos que dan lugar a derechos comunes de sus usuarios en una relación de cooperación y solidaridad, donde el dinero sólo juega un valor secundario. ${ }^{14}$

Sin embargo, los recursos de uso común (RUC) enfrentan mayormente serios problemas de sobreuso y del polizón o gorrón, ${ }^{15}$ para cuya solución Ostrom ha diseñado un régimen regulativo sujeto a condicio-

13 Helfrich, S. et al., op. cit., pp. 30 y ss.

14 Mientras en una economía de bienes comunes todos tienen la misma influencia y pueden integrarse con iguales derechos, en sociedades de capital el dinero decide el nivel de influencia, Helfrich, S. et al., op. cit., pp. 5 y 13.

${ }^{15}$ En general, los seres humanos enfrentan por lo menos dos problemas de incentivo en el uso de los recursos comunes: el sobreuso y el polizón o gorrón, Ostrom, E. et al. (eds.), The Drama of the Commons, cit., pp. 18 y ss. El sobreuso, que puede llevar a la destrucción del bien, ocurre cuando el uso de una persona sustrae el beneficio disponible de los demás. El problema del polizón, en su forma extrema, es la imposibilidad de excluir a beneficiarios cuando se han hecho progresos en esos bienes: "If it is not practical to exclude a user nor possible to force that user to contribute to the costs of developing and maintaining the resource, the noncontribuiting user is called a free rider", ibidem, p. 19; "One 'solves' the free-rider problem when rules are adopted and accepted that regulate individual actions so that social benefits and social costs are taken into account.”, ibidem, pp. 19 y ss. 
nes determinadas que aseguren su éxito o efectividad. Primero, debe tratarse de una acción colectiva autoorganizada, autorregulada y autoadministrada por los actores o usuarios mismos, estipulada mediante un acuerdo contractual y vinculante de cooperación. ${ }^{16}$ La misma debe contener reglas coherentes y claramente definidas por los participantes que determinen la apropiación, las formas de uso y cooperación, la restricción, el aprovisionamiento, la distribución, etcétera, las decisiones deben ser tomadas colectivamente y con la participación de sus miembros en su modificación; debe existir un mecanismo de supervisión y control recíproco del cumplimiento de las reglas, de sanciones graduales o proporcionadas contra el incumplimiento, y un mecanismo de resolución de conflictos, así como de un reconocimiento exterior del derecho de autoorganizarse; por último, deben existir múltiples niveles de organización interna y coordinación en recursos que son parte de sistemas más grandes. ${ }^{17}$ Se trata aquí pues, de un sistema colectivo bastante complejo que pretende ser alternativo y no sustitutivo al del mercado y Estado, siendo importante el papel de este útimo en tanto otorgue las condiciones para su realización y garantice la realización de las sanciones.

Este régimen autogestionario presupone además, la existencia de múltiples factores que garanticen su efectividad, medida en eficiencia, equidad y sostenibilidad, ${ }^{18}$ como la competencia, visible en la posesión de información y conocimiento científico y local; un capital social para solucionar los problemas de carácter institucional, y la suficiente autonomía para levantar y modificar las correspondientes estructuras institucionales. Sin embargo, los factores precondicionantes de su éxito están dados en el fin común de compartir el bien común para el beneficio mutuo, unido a una estrategia de cooperación que contenga la acción de compartir y participar de sus miembros. Para lograr una verdadera cooperación son imprescindibles, a la vez, la comunicación directa

${ }^{16}$ Ostrom, E., The Logic..., cit., pp. 43 y ss., 57y ss.

17 Ibidem, pp. 290 y ss.

18 Ostrom, E. et al. (eds.), The Drama of the Commons, cit., pp. 25 y ss. El criterio de eficiencia económica se basa en la relación entre los beneficios individuales y sociales totales, y los costos individuales y sociales totales. El criterio de la equidad evalúa la distribución de los costos y beneficios con base en una relación entre las contribuciones individuales y los beneficios que derivan o en su habilidad diferencial de pagarlos, idem. 
Esta revista forma parte del acervo de la Biblioteca Jurídica Virtual del Instituto de Investigaciones Jurídicas de la UNAM

entre los usuarios, cierto grado de reciprocidad, confianza, reputación y solidaridad entre ellos; condiciones que presuponen la existencia de una relación de igualdad de derechos e independencia entre los actores, excluyente de toda jerarquía, dominio o poder de uno sobre otro; ${ }^{19}$ la que requiere de una relación fáctica de equidad o balance entre ellos. Se trata, pues, esencialmente de una economía de compartir y de participación. ${ }^{20}$

Como se puede observar, son principios rectores de los bienes comunes los principios de eficiencia, equidad y sostenibilidad, los que están fuertemente vinculados con los principios de igualdad, libertad, responsabilidad, comunicación, sociabilidad, reciprocidad, confianza, solidaridad y cooperación; todos ellos juegan el doble papel de ser presupuestos de la realización de los bienes comunes y sus principios fundamentales. Otros conceptos que los apoyan son el de transparencia, democracia interna y justicia intergeneracional, que contribuyen a la cohesión social de este régimen. Principios todos éstos que tienen alta relevancia porque no son meros productos de especulaciones filosóficas, sino han sido valorados por la ciencia económica como factores condicionantes del éxito de los bienes comunes.

Asimismo, se hace necesario distinguir el concepto de bienes comunes con otros afines como los de propiedad común, bienes públicos y bienes sin dueño, con los que suele confundirse. Con respecto a la propiedad común, ${ }^{21}$ el concepto de bienes comunes es más amplio, pues incluye otras formas de relaciones de los hombres con los bienes que el de la propiedad. En cuanto a los bienes públicos, la diferencia más notoria está en que éstos no ocasionan rivalidad en el uso o consumo y necesitan de una decisión política para su abastecimiento, por ende, de un rol fuerte del Estado, ${ }^{22}$ mientras los bienes comunes pueden ser

19 Condición que no remarca expresamente Ostrom, pero parece implicarla al referirse a los factores internos contribuyentes de su fracaso, citando el caso de individuos poderosos que se benefician del status quo y bloquean los intentos de los menos poderosos de cambiar las reglas de juego, Ostrom, E., The Logic..., cit., p. 51; más clara en Helfrich, S., op. cit., p. 13, 15; Helfrich, S. et al., op. cit., p. 5.

${ }^{20}$ Helfrich, S. et al., op. cit., p. 41.

${ }^{21}$ O propiedad colectiva en sus formas de cooperativa, condominio, herencia colectiva, sociedad anónima, etcétera.

${ }^{22}$ Es necesario aquí subrayar la clara distinción entre bienes públicos y bienes comunes, 
Esta revista forma parte del acervo de la Biblioteca Jurídica Virtual del Instituto de Investigaciones Jurídicas de la UNAM

rivales y excluyentes, y tienen la característica de ser gestionados por los mismos usuarios. Pero la confusión más persistente y duradera, que proviene desde su creación en la Antigüedad, está en equipararlos con los bienes sin dueño o res nullius, o en el lenguaje moderno de los commons, con el "open access". ${ }^{23}$ Mientras éstos son libres, no están regulados y son objeto de apropiación privada directa, los bienes comunes están sujetos a regulación y no pueden ser apropiados individualmente; de ser este último el caso, se estaría ante la situación del "cercamiento o confinamiento de los comunes" ${ }^{24}$ y por tanto, de su desaparición. Los bienes comunes surgen sólo cuando la comunidad de usuarios logra reglamentar su acceso, uso y/o producción. Precisamente esta falta de diferenciación llevó a Hardin a cometer el error de considerar los bienes comunes como res nullius y tuvo que corregir años después su "tragedia de los bienes comunes" por una "tragedia de los bienes comunes no regulados". ${ }^{25}$

sobre todo debido a que los primeros, en su dimensión global y bajo el nombre de "bienes públicos globales" (global public goods), están gozando últimamente de gran coyuntura dentro de la ONU — a través del PNUD con estudios y publicaciones apreciables en su página web http: / / web.undp.org/globalpublicgoods/ (2 de agosto de 2013) - y empiezan a ser tratados en el derecho internacional público. Son elementos extraños a los bienes públicos: un sistema descentralizado y autogestionario de coproducción, el acceso igual y justo a los recursos, la participación y acuerdo de todos en su gestión y distribución, la igual carga de costos y el beneficio directo individual y general de sus miembros. A parte de estas diferencias, los bienes públicos globales tienen un desarrollo paralelo al de aquéllos y se sirven de otras herramientas conceptuales y de trabajo, como la existencia clara de un manejo concentrado en una institución o autoridad, que implica una relación vertical o jerárquica, siendo sus conceptos relevantes: gobernabilidad, burocracia, servicios, legitimidad, globalización, pluralismo jurídico internacional, derecho global, etcétera. Sobre su tratamiento desde una visión pragmática y técnica del derecho internacional véase Bodansky, D., "What's in a Concept? Global Public Goods, International Law, and Legitimacy”, EJIL, vol. 23, 2012, 3, pp. 651-668; Schaffer, G., "International Law and Global Public Goods in a Legal Pluralist World”, EJIL, vol. 23, 2012, 3, pp. 669-693; trabajos similares se encuentran en la misma edición del EJIL mencionado, siendo evidente en ellos de que el tratamiento de los bienes públicos globales tiene poco o nada que ver con el de los bienes comunes.

${ }^{23}$ En un régimen de open access un recurso de uso común (RUC) no tiene instituciones que gobiernan su uso, Ostrom, E. et al. (eds.), The Drama of the Commons, cit., p. 21.

${ }^{24}$ Heinrich Böll Stiftung (ed.), ¿Qué son bienes comunes?, México, 2007, p. 4, http: / /www. boell-latinoamerica.org/downloads/carpeta_bienes_comunes.pdf (1 de mayo de 2013).

25 Hardin, G., "Extensions of 'The Tragedy of the Commons'”, Science, 280, 1998, 682 683, p. 682; Helfrich, S., et. al., op.cit., p. 17. 
Por último, se puede decir que en el mismo hombre está identificar los bienes comunes del presente y hacerlos crecer en número para su propio beneficio, tanto individual como colectivo, constituyendo tal acción una seria alternativa y propuesta política diseñada para regir el futuro de las relaciones de los hombres con recursos no renovables y recursos vitales agotables, como el agua potable, y animar a toda persona, organización o sociedad a crear más de ellos, ya sea a nivel grupal, local e incluso global. En este último caso, que es de nuestro interés especial por estar en el foco del presente trabajo, sólo se puede hablar de una meta a alcanzar a largo plazo, o quizás una utopía, dada la multiplicidad de dificultades que están unidas a su manejo, aparte de la existencia aún escasa de investigaciones en el área. ${ }^{26}$

\section{Los bienes comunes globales}

Las investigaciones hechas sobre los bienes comunes, principalmente desde la ciencia económica, se limitaron, en un primer orden, a un espacio reducido, es decir, a un nivel local hasta regional, sin alcanzar a bienes globales como los fondos marinos, el alta mar, la atmósfera, el clima, la Antártida, el espacio ultraterrestre, que, dada su naturaleza y dimensión no pueden ser incluidos en tales estudios sin más. Por tratarse de bienes de importancia vital para la subsistencia del hombre o de relevancia económica para éste, y por el hecho de ser agotables, también están expuestos al sobreuso con su consecuente deterioro y/o destrucción, estando latente la seria situación problemática del polizón o gorrón.

Mas es necesario advertir que los recursos naturales globales o commons globales mencionados arriba, no son "bienes comunes" en el sentido estricto de la palabra y tal como está diseñado en la visión de Ostrom, sino muchos de ellos siguen perteneciendo a las categorías de bienes libres e incluso res nullius, cuyo acceso es libre y cuya reglamentación escasa o nula permite su uso y/o explotación individual ilimitado, hasta su apropiación, con el consiguiente deterioro del bien, como

${ }^{26}$ Los estudios de Ostrom se limitan a los RUC renovables locales, sin extenderse a recursos no renovables, energéticos o minerales, ni bienes comunes intangibles. 
ocurre en la zona del alta mar, la atmósfera o con el fenómeno del cambio climático, donde se presenta la situación dramática de que el acceso libre y general está a disposición de cualquier usuario, y cada uso que se hace del bien le quita a éste de su capacidad de servir o ser aprovechado por otros. Otro número más reducido de recursos globales como el espacio sideral, los cuerpos celestes y los fondos marinos, sí están considerados como bienes comunes al estar sujetos al régimen jurídico del patrimonio común de la humanidad; sin embargo, tal regulación es tan débil o rala que en último caso ellos siguen las leyes de la economía libre de mercado mundial, enfrentando también los mismos problemas de los bienes libres, es decir, el sobreuso y el polizón. Se presentan, entonces, dos niveles de problemas en los recursos globales. Uno que corresponde a su transformación de bienes libres o res nullius en "bienes comunes globales", y el otro que tiene que ver con aquellos espacios ya reconocidos como "bienes comunes globales" en la expresión moderna de patrimonio común de la humanidad, que deben ser sometidos a un escrutinio actual para determinar su verdadera calidad de bienes comunes, teniendo en cuenta los aportes de Ostrom y colegas.

En el caso de los commons globales no regulados y que caen dentro del ámbito de bienes libres o res nullius, se presenta la cuestión de si su transformación al régimen de bienes comunes representa una verdadera alternativa para un manejo razonable, y si los aportes científicos sobre los recursos comunes locales pueden servir de modelo o referencia para su tratamiento. Ambas cuestiones pueden responderse en un principio de forma afirmativa. En cuanto a la primera, ciertamente parece no haber otra alternativa éticamente razonable que transformar estos recursos en bienes comunes para asegurar su manejo eficiente, equitativo y sostenible para el beneficio de las generaciones presentes y futuras, ya sea bajo un régimen autorregulado, como propone Ostrom, o como patrimonio común de la humanidad, o incluso creando uno nuevo a partir de estas dos propuestas.

Una segunda opción que se presenta es la de humanizar o individualizar estos bienes en el sentido que su acceso sea considerado un derecho humano, como es la tendencia actual que se sigue en la ONU, ${ }^{27}$ o tratar- 
los como derechos humanos colectivos en la forma de un "derecho de participación al patrimonio común de la humanidad”; ${ }^{28}$ mas estas vías, aún en el mejor de los casos que se materialicen en derecho positivo internacional, no proporcionan soluciones a los problemas del sobreuso y del polizón o gorrón. Ello se hace patente en el problema del agua potable, que ha sido descubierta como el "oro azul del siglo XXI" por inversores privados y empresas multinacionales, y cuyo acceso ha sido declarado por la ONU como "derecho humano", pues este carácter no impedirá la privatización de su acceso y/o producción, tampoco su comercialización, ni menos el control y monopolio privado internacional sobre ella, ni su escaseamiento natural o artificial, ni, por último, las muertes de miles de personas pobres en el Tercer Mundo por no poder pagar el precio para acceder a ella. Aquí el discurso de los derechos humanos se queda corto frente a este problema global de apropiación, y esto pasaría con los demás recursos globales. Tampoco es adecuada su transformación en derechos humanos porque ello sólo sería posible con recursos vitales al ser humano, como el agua, mas no con otros recursos no vitales pero de valor económico excepcional, como sucede con los recursos de los fondos marinos o los cuerpos celestes, además de que una ampliación del ámbito de aplicación de los derechos humanos a estos recursos corre el peligro de vaciar a los primeros o deformarlos conceptualmente, mermando con ello en su fuerza de validez. Los derechos humanos, vistos como la panacea de cualquier problema ético-jurídico en tiempos de predominio del individualismo liberal, otorgarían a cualquier persona sólo la ilusión de poseer un "derecho" individual a estos bienes, mientras otros se benefician de su uso y explotación. La idea de los bienes comunes globales, en cambio, garantiza su uso colectivo de y para todos los seres humanos. Sería, al final, incoherente interpretar los recursos globales en clave de derechos humanos porque se individualiza y fragmenta más su acceso a ellos. Una tercera alternativa

marzo de 2010. Sobre este nuevo derecho véase Riedel, E. y Rothen (eds.), The Human Right to Water, Berlín, Berliner Wissenschafts-Verlag, 2006.

28 De forma clara como "derecho humano colectivo" o "derecho de tercera generación" en el artículo 22 de la Carta Africana de Derechos Humanos y de los Pueblos (Carta de Banjul) de 1982; a esto con más profundidad véase Witschen, D., Christliche Ethik der Menschenrechte: Systematische Studien, Litt, Hamburg 2002, pp. 169 y ss. 
estaría en declararlos como bienes públicos, vía que es sólo procedente si este estatus es transitorio y conducible al régimen de los bienes comunes, a fin de tender sobre estos recursos un manto protector frente a la codicia individual. La cuarta alternativa, la del status quo o dejar las cosas como están, es decir, dejar a estos recursos seguir el destino de los bienes libres y res nullius, sujetos directa o indirectamente a la apropiación privada, con la situación del polizón que desemboca en la "tragedia de los comunes", es un estado no justificable ni tolerable moralmente porque se sigue aceptando la situación perversa de que la ganancia de su uso y/o explotación estén privatizados, mientras los costos de estas actividades estén socializados en la humanidad del presente y de las generaciones futuras, teniendo que pagar ésta tales costos sociales.

En cuanto a la segunda cuestión, el modelo institucional de los recursos comunes de Ostrom sí puede servir de base para el tratamiento de los commons globales, ya que éstos enfrentan los mismos problemas que aquéllos, con la diferencia de que lo hacen a un nivel macroeconómico o universal. Mas su papel como modelo es insuficiente o limitado, dada la extensión de los recursos y el número de actores que usan, participan o deciden, junto a su alto grado de heterogeneidad o desigualdad económica, política, geográfica, social, cultural, etcétera, ${ }^{29} \sin$ mencionar los altos costos de autogestión, autoadministración, supervisión y control recíproco, que en su conjunto son factores que afectan negativamente en el nivel de cooperación, requisito indispensable para todo régimen de bienes comunes. Sobre todo el alto grado de heterogeneidad o desigualdad con la consiguiente asimetría en la capacidad o poder económico, político, científico, tecnológico y militar de los Estados, es gérmen del enfrentamiento de posiciones contrarias, llevándolos a elegir indistintamente una u otra alternativa arriba descrita, guiados por su posición e interés individual. A ello va unido la inexistencia de la confianza necesaria para la cooperación a este nivel, por encontrarse los Estados en una carrera de competición que sigue las leyes del mercado globalizado y va en la dirección contraria de la idea de los bienes

\footnotetext{
29 Bardahn y Dayton-Johnson, "Unequal Irrigators: Heterogenity and Commons Management in Large Scale Multivariate Research", Ostrom, E. et al. (eds.), The Drama of the Commons, cit., 87-112, pp. 88 y ss. Sobre bienes comunes al nivel global véase Keohane y Ostrom (eds.), Local Commons and Global Interdependence, Londres, Sage Publications, 1995.
} 
comunes, problemas que se verán más de cerca al tratar el régimen del patrimonio común de la humanidad.

Ahora pasaremos a desarrollar la segunda cuestión, de si los bienes sujetos al régimen del patrimonio común de la humanidad tienen verdaderamente la calidad de bienes comunes globales en el estado actual del sistema internacional, entendiéndose éste como el sustrato sociológico del derecho internacional.

\section{EL RÉGIMEN JURÍDICO MODERNO DE LOS BIENES COMUNES: PATRIMONIO COMÚN DE LA HUMANIDAD}

\section{El concepto de patrimonio común de la humanidad}

Como se ha mencionado arriba, sólo un número muy reducido de recursos globales goza del estatus jurídico de bienes comunes, que en su forma moderna está entendido bajo el concepto de patrimonio común de la humanidad. Estos recursos son: los fondos marinos, el espacio ultraterrestre y los cuerpos celestes y, con reservas, la Antártida. El clima, que es también un common global, no está sometido a este régimen, aunque se encuentran algunas aproximaciones a él en los conceptos de "common concern of mankind", "common interest" o "common responsibility and co-operation". ${ }^{30}$

El término de patrimonio común de la humanidad (PCH) surge en los años sesenta del siglo XX como uno de los conceptos más utilizados en el diálogo Norte-Sur y como parte importante de las exigencias del tercer mundo por un nuevo orden económico internacional. ${ }^{31}$ Fue dado a conocer en la ONU por el embajador de Malta, Arvid Pardo, en 1967,

30 Wolfrum, R., "Common Heritage of Mankind", Max Planck Encyclopedia of Public Internatrional Law, Oxford University Press, 2012, 452-458, p. 454; similarmente, el concepto de "patrimonio mundial" de la UNESCO tiene un significado simbólico que no llega al concepto de bien común; de otra opinión Kiss, A., "The Common Heritage of Mankind: Utopia or Reality?”, 40 Int '1 J. 1984-1985, 423-441, p. 433.

${ }^{31}$ Kewenig, W. A., "Common Heritage of Mankind-Politischer Slogan oder völkerrechtlicher Schlüsselbegriff?”, Von Münch, I. (ed.), Staatsrecht-Völkerrecht-Europarecht, Berlín, Gruyter, 1981, 385-406, pp. 385 y ss. 
Esta revista forma parte del acervo de la Biblioteca Jurídica Virtual del Instituto de Investigaciones Jurídicas de la UNAM

en conexión con los fondos marinos y sus recursos más allá de las jurisdicciones nacionales, ${ }^{32}$ y por el embajador argentino Cocca, unos meses antes, al tratarse el tema del espacio ultraterrestre, ${ }^{33}$ existiendo ya en ese entonces en los Estados la convicción general de que el uso de estos espacios debe contribuir al desarrollo de todos los pueblos. ${ }^{34}$ Mas fue Pardo quien diseñó los contornos de este concepto dentro de la ONU. Inspirado en el principio de equidad internacional y en vista de la agotabilidad de los recursos marinos, propuso declarar esta área de interés de la humanidad y señaló sus elementos de no apropiación por ningún Estado o ente en particular; su exploración e investigación en consistencia con los propósitos y principios de la Carta de la ONU y en salvaguarda de los intereses de la humanidad; su uso en interés de todos, promoviendo sobre todo el desarrollo de los países pobres de los beneficios de su explotación; la perpetuidad del uso pacífico, y por último, la creación de una autoridad. ${ }^{35}$ Siguiendo esta iniciativa, la Asamblea General de la ONU aprueba en 1970 una Resolución que declara los fondos marinos como $\mathrm{PCH},{ }^{36}$ la misma que va a constituir la base legal de partida para

${ }^{32}$ UN Doc. A/6695, 18 de agosto de 1967.

33 A esto véase Wolfrum, R., "The Principle of the Common Heritage of Mankind”, ZaöRV 1983, 312-337, p. 312.

${ }^{34}$ UN Doc. A/Res. 2172 (XXI), 6 de diciembre de 1966. Es conocida la memorable frase del Presidente Johnson de Estados Unidos en 1967, de "velar para que las profundidades y lechos marinos sean y se mantengan como legado de todos los seres humanos", Sohn, L. B., "Explotación del Lecho Marino fuera de la Plataforma Continental”, Revista Integración, 1968, 123-143, p. 124, así como las contribuciones al $\mathrm{PCH}$ y posición positiva de las administraciones Nixon, Ford y Carter. Estados Unidos en los años setenta no sólo lo reconoció, sino buscó cimentarlo en una convención trayendo propuestas para el proyecto de la Convemar como el sistema paralelo y la transferencia financiera a la Empresa con la debida transferencia tecnológica minera para las actividades de explotación, véase Steinacker, K., The Legal Principles of the Common Heritage of Mankind and DeepSea-Bed Mining aoutside the U.N. Convention of the Law of the Sea, Berlín, Wisseschafticher Autoren-Verlag, 1985, pp. 40 y ss.

35 Kewenig, W., op. cit., p. 388. El 17 de agosto de 1967 Arvid Pardo propuso a la Asamblea General de la ONU la preparación de un convenio internacional sobre un derecho del mar moderno y más acorde a los intereses del tercer mundo, en vista del peligro de apropiación de los recursos naturales del mar por países que postulaban la libertad de los mares y la competencia libre, véase UN Doc. A/6695, 17. 08.1967 y UN Doc. A/C.1/PV.1515 y A/C.1/ PV.1516, 1.11.1967; véase Kewenig, W., op. cit., pp. 387 y ss.; French, G. A., Der Tiefseebergbau, Carl Heymanns Verlag KG, Köln 1990, pp. 158 y ss.

${ }^{36}$ Declaración de Principios que regulan los fondos marinos y oceánicos y su subsuelo 
Esta revista forma parte del acervo de la Biblioteca Jurídica Virtual del Instituto de Investigaciones Jurídicas de la UNAM

el desarrollo del concepto de PCH y de su plasmación fija como norma iusinternacional varios años después en la Convención sobre el Derecho del Mar de 1982 (Convemar), siendo que a tal fecha ya todos los Estados, sin excepción, habían reconocido el principio en sí. ${ }^{37}$ Igualmente, el 27 de enero de 1967, se cristaliza la idea del PCH como norma iusinternacional en el Tratado sobre el Espacio Ultraterrestre, ${ }^{38} \mathrm{y}$ años después, de forma más concreta, en el Tratado de la Luna de 1979. ${ }^{39}$

Como se puede ver, originalmente el $\mathrm{PCH}$ fue concebido, primero y ante todo, como un concepto legal sobre la participación equitativa de los recursos naturales localizados más allá de la jurisdicción nacional, y que más concretamente, busca la igual participación de todos los Estados, en especial de los menos desarrollados, en el proceso de decisión sobre estos espacios. ${ }^{40}$ Posee carácter de principio jurídico al haberse cimentado legalmente en la conciencia de todos los Estados a través de resoluciones y convenios, y por contener una serie de enunciados o normas que rigen para estos espacios. Su fundamento básico está en el principio general de justicia y en sus principios derivables de equidad,

fuera de los límites de la jurisdicción nacional, Res. 2749 (XXV) AG-ONU, 17 de diciembre de 1970 que reafirma el libre acceso a todos y su exploración y explotación en interés de la humanidad en conjunto, con particular interés de los países en desarrollo. Antecedida por otra controvertida que establece un moratorium de explotación de los fondos marinos, UN GA Res. 2574 A (XXIV), 15 de diciembre de 1969.

${ }^{37}$ Kewenig, op. cit., p. 391, 393, para quien todos sus elementos (la prohibición de la apropiación, el uso exclusivamente pacífico, la cooperación en la investigación científica, la prevención del daño a la flora y fauna y la necesidad de una autoridad), fueron aceptados unánimemente por los Estados, incluída la moción de que los beneficios de su uso recaigan en todos y no sólo en quienes los explotan; elementos controvertidos en los detalles fueron los derechos de uso y la configuración de la autoridad. El autor afirma su carácter de principio del derecho internacional público general, ibidem, p. 402.

38 Tratado sobre los Principios que deben regir las Actividades de los Estados en la Exploración y Utilización del Espacio Extraterrestre, incluso la Luna y otros Cuerpos Celestes, del 27 de enero de 1967 y en vigencia desde el 10 de octubre del mismo año.

39 Tratado vigente desde 1984, firmado y ratificado por un número muy reducido de Estados, sin contar con las potencias espaciales mundiales.

40 "The CHM is therefore, first and foremost, a legal concept of equitable sharing of natural resources located beyond national jurisdiction, and one that aims at the equal participation of all States, in particular the less developed ones, in the decision-making process relating to such sharing", Shraga, D., "The Common Heritage of Mankind: The Concept and its Application”, Annales D’Études Internationales, vol. 15, 1986, 45-63, p. 63. 
Esta revista forma parte del acervo de la Biblioteca Jurídica Virtual del Instituto de Investigaciones Jurídicas de la UNAM

igualdad global genuina y material, y de responsabilidad social, ${ }^{41}$ los que tienen a la humanidad como beneficiaria de su uso y/o explotación, la misma que está representada de facto por los Estados, estando constituida por todos los individuos, pueblos, Estados, y generaciones de hoy y del futuro. El núcleo del concepto del $\mathrm{PCH}$ consiste pues, en la participación justa de los recursos globales, siendo secundarios todos los demás elementos. La conclusión inmediata es que no se puede hablar de $\mathrm{PCH}$ sin un sistema de participación en los recursos. ${ }^{42}$

Sin embargo, la concretización del contenido de su elemento central como de los secundarios, que no quedó resuelto en la UNCLOS III de 1982, representó desde un principio un problema serio para el alcance del principio, no sólo debido a los componentes más controvertidos como fueron el uso y la administración, sino sobre todo, por el cambio radical de postura de los países altamente industrializados, liderados por Estados Unidos, que a partir de los años ochenta mostraron una postura de soslayo y hasta rechazo abierto del principio en sí para aferrarse nuevamente a la idea de la "libertad de los mares" o del acceso libre. Veamos ahora brevemente cómo está configurado el principio del $\mathrm{PCH}$ en estos commons globales.

${ }^{41}$ Para French la diferencia entre el principio de libertad de los mares y el de PCH radica precisamente en el mandato de justicia de este último, ausente en aquél, French, G. A., op. cit., p. 163. Similarmente en Shraga, los principios de equidad, explotación planeada y controlada y participación equitativa de los beneficios para todos, reemplazarían a los principios tradicionales de apropiación nacional, libertad de los mares y libre acceso a sus recursos, Shraga, D., op. cit., p. 46. El elemento de la participación justa no está expresamente mencionado por Kewenig, pero sí en Shraga, para quien el principio de una participación justa y equitativa entre las naciones es parte central o indispensable del concepto del $\mathrm{PCH}$, siendo los otros elementos secundarios, Shraga, D., op. cit., p. 45, 59; a esto véase también Anand, R. P., "Common Heritage of Mankind: Mutilation of an Ideal" Indian Journal of International Law, vol. 37, núm. 1, 1997, 1-18, p. 6.

${ }^{42}$ Shraga, D., op. cit., pp. 59 y ss. Cfr. Kewenig, quien no hace depender el principio del PCH de un solo elemento, Kewenig, W., op. cit., p. 402; lo considera como principio jurídico, Steinacker, K., op. cit., p. 19; como concepto legal, Shraga, D., op. cit., p. 45; como un principio simplemente, Wolfrum, R., op. cit., p. 453. 
Esta revista forma parte del acervo de la Biblioteca Jurídica Virtual del Instituto de Investigaciones Jurídicas de la UNAM

\section{Los fondo marinos: del principio de la libertad de los mares al de PCH y viceversa}

Los fondos marinos, que recién fueron descubiertos e investigados en los dos últimos siglos, estuvieron anteriormente sujetos a las mismas reglas existentes sobre el mar. Éste a su vez comienza a ser diferenciado políticamente entre un mar costero bajo el poder soberano de los países que lo limitan y un mar más allá del ejercicio soberano de las aguas costeras, denominándose a éste "alta mar" ${ }^{43}$ Espacio que ha sido considerado libre hasta el presente, en virtud del principio iusinternacional de la "libertad de los mares" que emergió en el derecho internacional positivo de finales del siglo XVIII. ${ }^{44}$ El mismo prohibe su apropiación u ocupación, así como cualquier forma del ejercicio de soberanía o propiedad privada, a cambio de ser su uso y explotación "libres", es decir, estar a disposición de cualquier persona o Estado. Su elemento sustancial es pues, el derecho de libre acceso en conexión con las libertades de comunicación y navegación. ${ }^{45}$ La Convemar no hace más que confirmar las premisas de este principio, comprendiendo en él principalmente las libertades de navegación, pesca, deposición de cables submarinos y oleoductos, de vuelo sobre él, de investigación, y de uso militar, con el límite de tener en consideración las libertades de los demás Estados ${ }^{46}$ y determinadas res-

43 La Convención de Ginebra sobre el Alta Mar de 1958 codifica el derecho consuetudinario sin hacer una definición clara del alta mar ni establecer su extensión.

${ }^{44}$ Principio enunciado por Francisco de Vitoria y divulgado por Hugo Grocio, quienes vieron este espacio como un bien común. A esto dice Grocio: "The sea is common to all because it is so limitless that it cannot become a possession of one, and because it is adapted for the use of all, whether we consider it from the point of view of navigation or of fisheries", Grotius, Hugo, The Freedom of the Sea, Londres, Oxford University Press, 1916, p. 28; dirigido políticamente contra las pretensiones de dominio universal español y portugués, pero controvertido en la época debido a las pretensiones de dominio inglesas, respaldadas por el principio del mare clausum de Seldon.

${ }^{45}$ Steinacker, K., op. cit., p. 12. Nótese que el acceso libre tiene dos formas: una total, o como extensión del derecho de soberanía de los Estados en condición material de hacerlo; y otra en forma debilitada, como el principio de "libertad de los mares" que prohibe su apropiación y ocupación, pero su uso queda abierto a todos los Estados, a esto véase Kewenig, W., op. cit. , p. 403.

${ }^{46}$ Artículo 87, Convemar 1982, siendo tal enumeración enunciativa. 
tricciones específicas como la obligación de conservar los recursos vivos y ejercer maniobras militares que no impliquen el uso de la fuerza, ni pruebas atómicas u ocupación soberana. ${ }^{47}$

Sin embargo, en los tiempos de Pardo ya se empezó a ver las serias deficiencias de este principio frente a dos problemas relevantes que se presentan en su uso y/o explotación. Por un lado está el deterioro del medio marino debido a su sobreuso, ocasionado indistintamente por los Estados. Por otro lado está el incesante problema de la desigualdad en su uso y/o explotación, resultando un aprovechamiento económico mayor de los países más activos y uno menor o nulo de una gran mayoría de Estados con bajos medios económicos, situación que abre aún más la brecha entre Estados ricos y pobres, e incrementa aún más la desigualdad fáctica que merma al final en el derecho de igualdad de los Estados. Problemas que fueron discutidos doctrinariamente y debatidos suficientemente en la ONU, sin llegar a ser solucionados por el vigente derecho del mar, los que tendrán que ser tratados en el futuro.

Consciente de estos problemas, y a partir del descubrimiento de la posibilidad de explotación económica de los recursos minerales de los fondos marinos en la segunda mitad del siglo XX, surge el principio del $\mathrm{PCH}$ para esta área del alta mar de acceso extremadamente limitado y sólo posible con la ayuda de medios tecnológicos costosísimos. Los fondos marinos o "Zona" son aquellas regiones debajo del alta mar y fuera del zócalo continental que están a miles de metros de profundidad, en cuyas áreas se albergan cuantiosos recursos naturales minerales, biológicos y energéticos de importancia aún inestimable para el hombre y que pueden ser económicamente explotados por éste. Entre los recursos minerales que resguardan, están los nódulos polimetálicos, las costras ferromanganesíferas ricas en cobalto, y los sulfuros polimetálicos, recursos todos éstos que contienen altas concentraciones de minerales de gran importancia para la economía industrial moderna a pesar de los altísimos costos de prospección, extracción y explotación, ${ }^{48}$ habiendo sido conocidos solamente los primeros en la fecha en que Pardo lanzó el concepto del PCH. A parte de estos recursos, se encuentran organismos con propiedades únicas de vida, que también con posterioridad a

47 Artículos 61, 117 y ss., 88 y 89, Convemar 1982.

48 A esto véase French, G. A., op. cit., pp. 8 y ss. 
Esta revista forma parte del acervo de la Biblioteca Jurídica Virtual del Instituto de Investigaciones Jurídicas de la UNAM

la aprobación de la Convemar fueron descubiertos como recursos biológicos proveedores de sustancias medicinales y como material genético para la investigación en diversas áreas, cuya explotación económica, principalmente en la industria farmacéutica, es bastante prometedora. ${ }^{49}$ Asimismo, esta zona es rica en hidratos de metano que servirán como fuente energética en el futuro. Las investigaciones sobre los fondos marinos recién se está intensificando en los últimos años, esperándose en el futuro próximo nuevos descubrimientos de recursos naturales orgánicos e inorgánicos y nuevas formas de uso y/o explotación económica.

Los fondos marinos se someten recién de manera vinculante al régimen del PCH con la Convemar, que en su artículo 136 establece que "la Zona y sus recursos son patrimonio común de la humanidad" ${ }^{50}$ y determina los principios que la rigen, así como prescribe una serie de directivas para su tratamiento, administración, distribución y la creación de un organismo competente..$^{51}$ En este documento el PCH funge como un principio con sus reglas fundamentales de no apropiación, uso pacífico y sostenible, cooperación en la investigación científica e intervención de una organización internacional, conteniendo además una cláusula no derogativa en su artículo 311 (6). Hasta aquí el principio del $\mathrm{PCH}$ pa-

${ }^{49}$ Ni la Convemar de 1982, ni la Convención en Diversidad Biológica (CBD) regulan los estudios con fines de explotación comercial de estos recursos vivos. La ONU se ocupa actualmente sobre el tema; entre los diversos informes véase UNEP/CBD/SBSTTA/8/9/Add.3/ Rev.1, del 20 de febrero de 2003; y los del Grupo de Trabajo Especial de composición abierta UN Doc. A/59/122, UN Doc. A/61/65, UN Doc. A/63/111, de 2004, 2006 y 2008. Sobre la discusión actual de los recursos genéticos de los fondos marinos véase Molenaar, E. y Oude, A. (eds.), The International Legal Regime of Areas Beyond National Jurisdiction: Current and Future Developments, Leiden, Martinus Nijhoff, 2010.

${ }^{50}$ Tratado que hasta enero de 2013 fue ratificado por 165 Estados con exclusión de Estados Unidos, aún siendo éste el autor, propulsor y signatario del Acuerdo de Implementación de 1994 (véase infra n. 52).

${ }^{51}$ Se trata de la Autoridad Internacional de los Fondos Marinos (AIFM), compuesta por una asamblea, consejo, secretaría y la Empresa, cuyo poder es limitado, su presupuesto es pequeño y sus mayores contribuidores son los países industrializados. En 1983-84 concedió contratos preferenciales a "inversores pioneros" (4 firmas transnacionales de Estados Unidos, 1 de Francia, 1 de Japón, 1 de Unión Soviética y 1 de la India). Paralela y unilateralmente, los Estados Unidos, el Reino Unido, Francia y Alemania firmaron un Tratado sobre la explotación de los fondos marinos el 4 de febrero de 1982 (mini-tratado), seguidos por otros más, a esto véase Steinacker, K., op. cit. (n.34), pp. 40 y ss.; la Comisión de Expertos del Grupo de los 77 reaccionó y se adelantó en recalcar la importancia del principio de buena fe, y condenó toda acción unilateral, véase UN Doc.A/Conf.62/77 del 24 de abril de 1979. 
rece haberse asentado en el derecho del mar positivo y haberlo revolucionado. Pero el diablo se esconde en los pequeños detalles. A pesar de la claridad del artículo 136, está actualmente en discusión la cuestión altamente relevante de si el principio del PCH se extiende a los recursos naturales no previstos en esta convención como las costras ferromanganesíferas y los sulfuros polimetálicos, los organismos vivos que habitan allí, así como los hidratos de metano y otros recursos aún por descubrir en el futuro. En cuanto a los dos primeros, aunque la Convemar reguló los recursos de la Zona teniendo sólo en cuenta los nódulos polimetálicos, se puede decir que las costras ferromanganesíferas y los sulfuros metálicos, así como todo recurso mineral por descubrir, están incluidos dentro del régimen del PCH con base en el artículo 133 (parte XI) de la Convemar. En cuanto a los recursos vivos y energéticos, se hace a primera vista muy difícil su ordenación dentro de este régimen, ya que la convención misma, si bien se refirió en su parte general y preámbulo inequívocamente a los recursos en general que se encuentran en la Zona, definió, sin embargo, en la parte XI los “recursos" de la Zona muy estrictamente, es decir, sólo como "recursos minerales"; lo que ha revelado ser un error grave de los negociadores del tercer mundo, por haber aceptado una definición estricta y cerrada del concepto "recursos" dentro del régimen del $\mathrm{PCH}$, conociendo que este espacio estaba aún por explorarse..$^{52}$ Una solución a este problema se daría al recurrir a una interpretación dinámica o teleológica del artículo 136 de la Convemar — como se ha hecho con la Carta de la ONU — para que con base en el fin de protección de los recursos naturales vivos, minerales y energéticos, se los pueda incluir dentro del término "recursos", o alternativamente a través de un Acuerdo aclaratorio. Sin embargo, al volver a la realidad política internacional, tales propuestas no parecerán tener salida alguna, ya que la primera necesitará su cristalización en una opinio iuris y práctica internacional, y la segunda, en una decisión política firme de los Estados.

Un revés aún más fuerte que recibió la idea del PCH sucedió a los 12 años de haberse suscrito la Convemar y con motivo de su puesta en vi-

\footnotetext{
52 Ya en el siglo XIX se sabía de la existencia de organismos vivos, HMS Challenger Expedition en Natural History Museum, http://www.nhm.ac.uk/nature-online/science-of-naturalhistory/expeditions-collecting/hms-challenger-expedition/ (1o. de julio de 2013); pero el descubrimiento de su aprovechamiento económico es reciente.
} 
gencia, ya que se producen modificaciones importantes en la reglamentación de los fondos marinos por el Acuerdo Relativo a la Aplicación de la Parte XI (Implementing Agreement) de 1994, que van a vaciar de contenido el concepto del PCH. Así pues, se aceptó, entre otras cosas, el peso decisivo de Estados Unidos y países industrializados dentro de la Autoridad Internacional de los Fondos Marinos al asegurarse el primero de ellos un asiento en el Consejo y obtener junto con otros países industrializados la facultad de bloquear decisiones del Consejo; también esta potencia consiguió el poder de vetar cualquier modificación del régimen y el otorgamiento de sitios mineros a tres consorcios de liderazgo estadounidense en condiciones no menos favorables que las dadas a Japón, Francia, Rusia, India y China. Asimismo, se renunció al principio de transferencia tecnológica, a la limitación de la producción en protección de los intereses de los productores de minerales en tierra, al pago de los derechos de concesión y a la transferencia financiera y tecnológica a la autoridad y empresa, ${ }^{53}$ degradando además a esta última al nivel competitivo de las empresas de países explotadores. Con ello, el uso y la explotación de los fondos marinos van a estar regidos por las reglas imperantes del mercado mundial libre que no exige responder por los costos que conllevan estas actividades, redundando en un beneficio enorme para el capital privado que interviene en ellos y automáticamente en perjuicio de los intereses de la humanidad en su conjunto. La consecuencia de este cambio radical es que se terminó por extinguir toda esperanza de considerar los fondos marinos como "bienes comunes" y con ello, de un acceso y participación equitativos de sus recursos.

Agreement relating to the Implementation of Part XI of the United Nations Convention on the Law of the Sea of 10 December 1982 (UNCLOS), UN Doc. A/RES/48/263, 28 de julio de 1994. El acceso justo y equitativo estaba previsto con el "sistema paralelo", el que condicionaba la autorización de solicitudes de prospección a su sujeción al régimen de la Convención y decisiones de la autoridad. Asimismo, la autorización de exploración y explotación procedía una vez aprobado un plan de trabajo que indique los Estados esponsores, la capacidad financiera y tecnológica, la división del área proyectada en dos partes de valor igual comercial y el compromiso de transferencia tecnológica de explotación a la Empresa en condiciones comerciales justas y razonables, expirable en 10 años. La autoridad debía escoger una de las dos áreas y declararla "zona reservada”, cuya explotación correría a cargo de la empresa o países del tercer mundo. También se estableció un sistema de pago de derechos: en la solicitud de aprobación del plan de trabajo eran abonables 500000 USD y derechos anuales fijos, o de acuerdo a las ganancias. Los derechos de producción se estimaron a un 5\% del valor del metal trabajado en los primeros 10 años, después a $12 \%$. 
Esta cesión de derechos realizada a Estados Unidos y países altamente industrializados no sólo significó una capitulación de los logros alcanzados con mucho esfuerzo, producto de largas y duras negociaciones por los Estados del tercer mundo en los años sesenta y setenta, sino es un escarnio a la misma idea yacente en el principio del $\mathrm{PCH}$ de relaciones más justas y en igualdad de condiciones, que los mismos países industrializados habían aceptado en un comienzo. Por ello se hace incomprensible la existencia de este Acuerdo, el que no se debe tanto a la postura radical de Estados Unidos y los países que le siguieron, sino a la de los mismos Estados del tercer mundo o Grupo de 77 que participaron en él y se inclinaron ante todas sus demandas, abandonando este principio a cambio del placebo de la "universalidad". Esto es sólo un botón de muestra de las relaciones asimétricas de los Estados en la ONU vistas en el peso político de los países altamente industrializados —una minoría_, quienes determinan en la práctica los contenidos políticos y normativos del sistema internacional.

El vaciamiento del principio del $\mathrm{PCH}$ trae como consecuencia directa el "libre acceso" a la Zona y sus recursos, y con ello, el regreso y reimplantación del concepto antagónico de la libertad de los mares, desvaneciendo su verdadero estatus de $\mathrm{PCH}$. Con la multiplicación de los usos y formas de explotación económica y privada de esta zona, los países con alta tecnología se asegurarán de que el principio del $\mathrm{PCH}$ no pueda ser aplicado en el futuro, y en su lugar, cobre toda vigencia de facto el principio de la libertad de los mares y el de res nullius, ${ }^{54}$ por servir éstos mejor a sus intereses. Se tendrá, entonces, que renovar en el futuro las demandas para que los fondos marinos y todos sus recursos vuelvan a regirse por el principio del $\mathrm{PCH}$ con todas las consecuencias que ello implica, e iniciar un diálogo para solucionar los problemas de participación y beneficios económicos de su manejo, así como de los problemas medioambientales que se presenten, si los países no explotadores del tercer mundo y/o más pobres no quieren ser ellos mismos quienes terminen por enterrar definitivamente este principio.

${ }^{54}$ Sobre el principio de res nullius como contraposición al PCH véase French, G. A., op. cit., pp. 135 y ss. 
Esta revista forma parte del acervo de la Biblioteca Jurídica Virtual del Instituto de Investigaciones Jurídicas de la UNAM

\section{El espacio ultraterrestre y los cuerpos celestes}

El espacio ultratraterrestre y los cuerpos celestes han sido objeto de reglamentación internacional a raíz de los viajes interplanetarios tripulados y no tripulados que se llevaron con intensidad en los sesenta y setenta, y fue Aldo Armando Cocca, iusinternacionalista argentino, uno de los artífices en introducir la idea del PCH en la ONU en 1967, que inspirándose en el concepto de res communis humanitatis o cosa común de la humanidad o derecho de la civilización, propugnaba el sometimiento de las actividades en esta área para el bien de la humanidad. ${ }^{55}$ En la actualidad, el espacio ultraterrestre con sus cuerpos celestes están regidos principalmente por dos convenios internacionales: el Tratado sobre el Espacio Ultraterrestre del 27 de enero de $1967^{56}$ y el Tratado de la Luna del 5 de diciembre de $1979,{ }^{57}$ que reglamentan su exploración y uso. ${ }^{58}$

55 Cocca, A. A., "The Advances in International Law through the Law of Outer Space”, 9 Journal of Space Law (1981), 13-20, p. 14; id., Derecho Espacial para la gran audiencia, Buenos Aires, AACA, 1970, p. 26, 52; id., Consolidación del derecho espacial, Buenos Aires, Astrea, 1971, pp. Vis, XIII y ss. El autor por un derecho espacial de la humanidad y para la humanidad, siendo ésta sujeto del derecho espacial. Véase también el interesante trabajo de Seara Vázquez, M., Introducción al derecho internacional cósmico, México, UNAM, 1961, pp. 83 y ss., passim, donde trata con amplitud los conceptos de res communis y res nullius.

56 Tratado sobre los principios que deben regir las actividades de los Estados en la exploración y utilización del Espacio Ultraterrestre, incluso la Luna y otros cuerpos celestes, aprobado por Asamblea General, Res. 2222 (XXI), 19 de diciembre de 1966 y en vigor el 10 de octubre de 1967. Basado principalmente en dos declaraciones de Asamblea General: Res. 1721 (XVI), 20 de diciembre de 1961, y Res. 1962 (XVIII), 17 de octubre de 1963.

57 Acuerdo que rige las actividades de los Estados en la Luna y otros cuerpos celestes, aprobado por Asamblea General, Res. 34/68, en vigor desde el 11 de julio de 1984. Ratificado por un número muy reducido de Estados sin incluir las potencias espaciales. Su escasa aceptación posterior se debe principalmente a su mención concreta del principio de $\mathrm{PCH}$ y a la política conservadora y radical de la administración Reagan en los años ochenta.

58 Otros instrumentos parte de la normativa espacial son: el Acuerdo sobre el salvamento y la devolución de astronautas de 1967, el Convenio sobre responsabilidad de 1971 y el Convenio sobre registro de 1974, en vigor desde 1968, 1972 y 1976 respectivamente. Tienen también relevancia para el concepto de PCH los "principios relativos a la teleobservación de la Tierra desde el espacio”, UN Doc. A/RES/41/65, 1986; la "Declaración sobre la cooperación internacional en la exploración y utilización del espacio ultraterrestre en beneficio e interés de todos los Estados, teniendo especialmente en cuenta las necesidades de los países en desarrollo”, UN Doc. A/RES/51/122, 1996; y los “principios pertinentes a la utilización 
Esta revista forma parte del acervo de la Biblioteca Jurídica Virtual del Instituto de Investigaciones Jurídicas de la UNAM

Sin embargo, sólo el primero puede tenerse en cuenta como norma iusinternacional vigente en el derecho espacial actual, ya que el Tratado de la Luna, aunque norma positiva, ha perdido fuerza obligatoria por su escasa aceptación universal. Subsidiariamente a esta normativa especial, rigen los principios fundamentales del derecho internacional como la no agresión y la solución pacífica de las controversias.

El Tratado sobre el Espacio Ultraterrestre, considerado entretanto como la norma básica o fundamental del derecho espacial, establece en su artículo 1o. párrafo 1 que "la exploración y utilización del espacio ultraterrestre, incluso la Luna y otros cuerpos celestes, deberán hacerse en provecho y en interés de todos los países, sea cual fuere su grado de desarrollo económico y científico, e incumben a toda la humanidad". Aunque este artículo no menciona aún el nombre de "patrimonio común de la humanidad", suscribe este principio ante todo con la expresión "incumben a toda la humanidad", el mismo que constituye la clave de la legislación espacial, ${ }^{59}$ que propugna la idea de que el espacio ultraterrestre con sus cuerpos celestes es un "común global” frente al cual existe un interés legítimo de todos los Estados en su exploración y utilización, derivándose de este principio otros como el de cooperación y solidaridad, los que a su vez fundan derechos de participación de todos los Estados así como de obligaciones de hacer participar de tales actividades también a todos los Estados. Los derechos de participación incluyen su habilitación para ejercer actividades espaciales en iguales condiciones y su participación de los beneficios de tales actividades espaciales, haciendo necesario para ello una especie de compensación de intereses. Las obligaciones de hacer participar son de carácter positivo e implican el fomento para la participación de todos los Estados en su uso $^{60}$ y para la cooperación en la investigación espacial. Así pues, el prin-

de fuentes de energía nuclear en el espacio ultraterrestre”, UN Doc. A/RES/47/68, 1992. La tercera conferencia de la ONU sobre la exploración y utilización del espacio ultraterrestre con fines pacíficos (UNISPACE III) del 19-30 de julio de 1999 en Viena, sólo realizó un balance de esta normatividad y divisó problemas como la comercialización de las actividades espaciales.

${ }^{59}$ Hobe, S., "Outer Space as the province of mankind - An Assessment of 40 years of development”, IISL/AIAA, Procedings of the fifth colloquium on the law of outer space, 24-28 sept. 2007, India, 442-449, p. 443.

${ }^{60}$ Wolfrum, R., Die Internationalisierung staatsfreier Räume, Berlín, Springer, 1984, p. 285. 
Esta revista forma parte del acervo de la Biblioteca Jurídica Virtual del Instituto de Investigaciones Jurídicas de la UNAM

cipio del PCH tiene el componente social de estar orientado a lograr una igualdad material o justicia distributiva. ${ }^{61}$ Sin embargo, la cooperación y solidaridad sólo están presentes aquí como ideas y no como una exigencia internacional. ${ }^{62}$

Otros componentes del principio del PCH que señala este Tratado están en la prohibición de apropiación nacional, ${ }^{63}$ que sólo se limita al área y no al uso (artículo II); el mandato de su utilización pacífica, que incluye su desmilitarización, aunque permitiendo toda clase de actividades militares de defensa (artículo IV); el principio de su uso razonable, que sólo debe tener en consideración los intereses de los demás Estados signatarios (artículo IX); la libertad de la investigación científica (artículo 1o., párrafo 3), y el principio de responsabilidad (artículos VI yVII). Elementos que se presentan en diferente fuerza y alcance, los que van a debilitar, también en diferente grado, el principio.

Aspectos que definitivamente contribuyen a su debilitamiento son la falta de un sistema regulatorio de participación de recursos ${ }^{64}$ que regule las diversas formas de uso y explotación económica no relacionados directamente con sus recursos naturales, pero que otorgan beneficios económicos significativos, y que en aquel tiempo no fueron divisados, como los vuelos suborbitales para fines turísticos o turismo espacial $;{ }^{65}$ la falta de una institución internacional que resguarde el interés de la humanidad, o mecanismo de administración, control y supervisión de las actividades espaciales; la ausencia de una interpretación autoritativa del

${ }^{61}$ El que es base para el desarrollo de una comunidad solidaria, Wolfrum, R., op. cit., p. 290; de forma similar dice Hobe: "The aim of the common province conception is thus to achieve a totally equal use of outer space by all states although the reality did and does not meet this parameter", Hobe, S., op. cit., pp. 443, 448.

${ }^{62}$ La cooperación es sólo voluntaria y bajo el principio de reciprocidad, como en la observación de actividades espaciales (artículo X), en el deber de informar sobre tales actividades, en el rescate de astronautas y en el registro de objetos espaciales, a esto Wolfrum, R., op. cit., p. 290.

${ }_{63}$ Principio que sólo puede estar limitado al área y no a sus recursos, siendo éstos res nullius, como sucede en el régimen de la Luna y cuerpos celestes y en el de los fondos marinos.

64 A esto Shraga, D., op. cit., p. 51.

65 Actividades comerciales que proporcionan las experiencias de los cosmonautas como la de ver la Tierra desde el espacio y experimentar la no gravitación, a esto véase Cloppenburg, J., "Legal Aspects of Space Tourism", en Benkö y Schrogl, Space Law: Current Problems and Perspectives for Future Regulation, Utrecht, Eleven, 2005, 191-214, p. 192. 
Tratado y de un régimen de solución de disputas, recayendo el control internacional en los mismos Estados activos en actividades espaciales. Asimismo, la obligación de cubrir daños y perjuicios en virtud del principio de responsabilidad, termina siendo voluntaria porque no faculta ejercer presión a los Estados para que observen el Tratado; similarmente, el mecanismo de inspección sólo funciona con base en el principio de reciprocidad y está destinado a asegurar la desmilitarización del espacio ultraterrestre. ${ }^{66}$

Por otro lado, este Tratado proclama en el mismo artículo 1o. el principio antagónico de la libertad espacial, que comprende las libertades de exploración, uso y explotación del espacio y sus cuerpos celestes para todos los Estados, garantizando expresamente el acceso libre a éstos. Libertad que es amplia por incluir toda clase de actividad, ya sea económica, científica, militar, etcétera, y abarca la totalidad del espacio con todos sus cuerpos celestes incluidos la Luna. Para Wolfrum se trata aquí de un principio fundamental y constitutivo del derecho espacial, que a la vez prohíbe a los Estados limitar tales actividades o impedirlas, el mismo que tiene sus límites en el principio del respeto del derecho internacional público, incluyendo la Carta de la ONU, y en el principio del $\mathrm{PCH}$, este último al que denomina "cláusula del bien común". ${ }^{67}$

La convivencia de los principios antagónicos del $\mathrm{PCH}$ y de la libertad espacial en el derecho espacial desde sus inicios, y las subsiguientes condiciones económico-políticas globalizadoras en el sistema internacional, que favorecieron a este último, han llevado a que el Tratado sea leído siguiendo la interpretación de Wolfrum, es decir, bajo la premisa de la libertad espacial; la que sirve en la actualidad a las tendencias privatizadoras y comercializadoras internacionales, y por tanto, a la apropiación privada del espacio ultraterrestre y sus cuerpos celestes, ${ }^{68}$ incluyendo su uso estratégico y militar por potencias espaciales y aliados ${ }^{69}$ que apuntan a una hegemonía espacial.

${ }_{66}$ Wolfrum, R., op. cit., pp. 280, 283.

67 Ibidem, pp. 279, 288, 294.

${ }_{68}$ El caso más grotesco se da en la venta de parcelas de la Luna por compañías estadounidenses como la de Denis Hope. A esto véase Doyle, S. E., "Issues of Sovereignty and Private Property”, en Benkö, M., Koll, W. (eds.), Luft undWeltraumrecht im 21. Jahrhundert, Carl Heymanns, Köln 2001, 313-325, p. 324.

${ }^{69}$ Se permite su uso militar “no agresivo”, a esto véase Wolter, D., Grundlagen, “Gemeinsamer 
Esta revista forma parte del acervo de la Biblioteca Jurídica Virtual del Instituto de Investigaciones Jurídicas de la UNAM

\section{La Antártida}

La Antártida ha sido relacionada también con el principio del $\mathrm{PCH}$, aunque no con la fuerza del régimen de los fondos marinos y del espacio ultraterrestre. Su situación jurídica actual sigue siendo incierta. Por un lado, se rige ante todo por el Tratado de la Antártida de 1959, vigente desde 1961, y su Protocolo de $1991^{70}$ que lo complementa. En el preámbulo de aquél, hace mención al "interés de la humanidad para que la Antártida se utilice con fines pacíficos”, prescribiendo su uso pacífico (artículo I), la libertad de investigación y cooperación (artículos II y III), y la prohibición de su uso como espacio de pruebas nucleares o depósito nuclear (artículo V). Sin embargo, este tratado no regula los derechos sobre el área, ni su acceso, tampoco el uso o explotación de sus recursos naturales, ni su participación o distribución equitativa, que evidentemente, no estuvo en sentido de los países signatarios. Su Protocolo sólo se limita a establecer una prohibición de las actividades mineras no científicas y un sistema amplio de protección y cooperación medioambiental, remarcando la importancia ecológica de esta región para el clima de la Tierra y los intereses ecológicos de toda la humanidad. ${ }^{71}$

Por otro lado, este régimen de la Antártida se encuentra en notoria contradicción con el principio del $\mathrm{PCH}$, ya que sigue latente la reclamación de derechos de soberanía e interés especial sobre esta área por parte de los 12 miembros consultivos del Tratado, que implica derechos preferenciales como el de apropiación territorial o económica frente a los demás Estados. ${ }^{72}$ La mención al "interés de toda la humanidad"

Sicherheit" im Weltraum nach universellemVölkerrecht, Berlín, Duncker \& Humblot, 2003; Sobre su control militar vid. Kries, W., "Legal Aspects of the Growing Military Uses of Outer Space" Benkö y Schrogl, op. cit., 141-153, p. 142.

${ }^{70}$ Protocolo al Tratado Antártico sobre Protección del Medio Ambiente (Protocolo de Madrid) vigente desde 1998.

${ }^{71}$ El documento designa a la Antártida como "reserva natural consagrada a la paz y a la ciencia"; el mismo posee un mecanismo de informes recíprocos e inspecciones, y de consultas para conflictos, sin llegar a establecer sanciones, ni su institucionaliación.

${ }^{72}$ Reclaman derechos soberanos: Reino Unido, Australia, Nueva Zelandia, Argentina, Chile, Francia y Noruega. Tienen interés en la zona sin reclamar derechos soberanos sobre ella: Bélgica, Japón, Sudáfrica, Estados Unidos y Rusia, a esto Wolfrum, R., op. cit., pp. 36 y ss. 
y la presencia de algunos elementos del principio del $\mathrm{PCH}$ tuvo el fin de evitar su apropiación y explotación económica por alguno de estos miembros consultivos, creándose con ello una situación de bloqueo recíproco o congelamiento de reclamaciones soberanas. A partir del Protocolo de 1991 este interés de la humanidad queda reducido a la protección del medio ambiente y con la reserva de la posición preferencial de estos Estados. La Antártida, entonces, no puede ser considerada como PCH. ${ }^{73}$ Se trata más que todo, tal como apunta Kimminich, de un espacio comunitario internacional en el cual un grupo de Estados se obligan a cooperar en un área especial. ${ }^{74}$

\section{5. ¿Qué ha quedado entonces del principio del PCH?}

El modelo de régimen jurídico más acabado y ambicioso del $\mathrm{PCH}$ se pudo encontrar en los fondos marinos. Sin embargo, el mismo adoleció de fallas desde su nacimiento, ya que no llegó a cubrir todos sus recursos, ni todas las formas de su uso económico, habiéndose concentrado sólo en el aprovechamiento económico de determinados recursos mineros; tampoco pudo llevar en la práctica el acceso igual y equitativo de sus recursos, ni llegó a crearse una autoridad internacional fuerte y representativa de la humanidad, que administre, controle y supervise todas las actividades en este espacio. Es así que este régimen, pensado para preservar los recursos naturales de la Zona de un acceso libre y desigual que desemboque en apropiaciones individuales, terminó doblegándose a éste, y, por tanto, dejó de ser un bien común de beneficio a la humanidad, y peor aún, se le dio el golpe de gracia con el Acuerdo de Implementación de 1994. A partir de entonces, la situación jurídica de los fondos marinos es tan incierta e insegura como para decir, sin lugar a dudas, que nuevamente cae presa del principio de la libertad de los mares, con su libertad de acceso, exploración y explotación de los recursos yacentes, y con una Autoridad que, además de ser una sombra de lo que se intentó crear en sus inicios, no podrá resguardar los intereses

\footnotetext{
73 V'éase Shraga, D. op. cit., pp. 55 y ss.

74 Kimminich, O., Einführung in das Völkerrecht, 6. Aufl., Tübingen, UTB Franke, 1997, p.
} 391. 
Esta revista forma parte del acervo de la Biblioteca Jurídica Virtual del Instituto de Investigaciones Jurídicas de la UNAM

de la humanidad, al ser muy fuerte el peso o influencia en ella de los países tecnológicamente ricos. Las cosas en cuanto al espacio ultraterrestre y cuerpos celestes son aún más desalentadoras, pues en esta área prima plenamente el principio de la libertad espacial. De la Antártida, no vale ni el esfuerzo referencial al $\mathrm{PCH}$.

Lo que empezó como un proyecto ambicioso de bienes no sujetos a la soberanía nacional de los Estados que debían ser destinados para el bien común de la humanidad, en virtud del principio del PCH, terminó en un fiasco, no tanto por el éxito de la política y diplomacia de Estados Unidos de los años ochenta y sus seguidores, los países altamente industrializados, que supieron muy bien defender sus intereses e imponerlos al final, sino ante todo, por el desvanecimiento de la lucha por este principio a cargo de los países del Tercer Mundo, o países no usuarios o no explotadores de la Zona o del espacio ultraterrestre, el que tiene que ver mucho, en primera línea, con el desmoronamiento del Bloque Soviético unido al robustecimiento de los Estados Unidos y el crecimiento de las relaciones de dependencia de los países del Sur pobre frente a aquéllos. ${ }^{75}$ El problema de los recursos comunes globales no sólo está en la heterogeneidad o desigualdad de países e intereses, sino en la estructura asimétrica escondida detrás de ella, la que hace difícil, sino imposible, una verdadera cooperación en virtud del principio quid pro quo, puesto que en un sistema anárquico como el nuestro, los Estados buscan como fin máximo asegurar su propia sobrevivencia. ${ }^{76}$

\section{LOS BIENES COMUNES EN LA VISIÓN DE FRANCISCO DE ViTORIA}

Las propuestas que dieron nacimiento al principio moderno del patrimonio común de la humanidad $(\mathrm{PCH})$ trajeron a colación en varias ocasiones la idea antigua de los bienes comunes. Tanto Pardo como Cocca hicieron mención de los términos latinos de res communis o res communes humanitatis. ${ }^{77}$ Por otro lado, la idea contemporánea de los commons, que

75 A esto véase Senghaas, D., "La gobernanza mundial y el derecho mundial en un mundo fragmentado”, Jueces para la Democracia, julio de 2010, 17-25, pp. 17 y ss.

76 Waltz, K., Theory of International Politics, Estados Unidos, Addison-Wesley P.C., 1979, p. 91.

77 Pardo y Cocca vieron en el concepto del PCH una superación de las res communis. No sin 
Esta revista forma parte del acervo de la Biblioteca Jurídica Virtual del Instituto de Investigaciones Jurídicas de la UNAM

trata Ostrom y colegas, también encuentra un antecesor en el concepto antiguo de los "bienes comunes" o res communis ommnium del derecho romano, el que formó parte importante de las teorías del dominio de siglos posteriores hasta el comienzo de la Modernidad. Es precisamente en la época de transición de la Edad Media a la Moderna que la idea de los bienes comunes es retomada por el fundador y representante más prestigioso de la Escolástica Tardía del siglo XVI, el dominico Francisco de Vitoria (1483-1546), no sólo para darle un lugar central en su teoría del dominio, sino también para solucionar el problema ético del colonialismo español en el Nuevo Mundo. En este último caso, ella sirvió de contenido del primer argumento de justificación de conquista y dominio, y por consiguiente, de justificación moral y jurídica de la política colonial española, adquiriendo con ello esta idea la calidad de doctrina política fundada en el derecho y la moral. ${ }^{78}$ Se hace necesario pues, echar una mirada breve al sistema teórico del dominio en el dominico.

La teoría del dominio de Vitoria, que forma parte importante de su teoría de la justicia, está construida con base en un concepto amplio de dominio y una teoría del origen del dominio. El concepto amplio de dominio, que es igualable al de ius o "derecho" en sentido de una facultas utendi re, es una facultad propia de todos los seres humanos por presuponer la racionalidad, la voluntad y el libre arbitrio para hacer uso de un bien, y comprende tanto un derecho individual de propiedad como un derecho público o dominio superioritatis, o derecho de los príncipes de gobernar a sus súbditos, siendo este último antecesor al concepto moderno de soberanía.

La teoría del origen del dominio, que es el fundamento teórico de la propiedad privada y del poder político, ${ }^{79}$ tiene dos órdenes. Uno es el dominium omnium o communis omnium possessio u orden en el que existía

razón el primero vinculaba a éstas con el principio de la libertad de los mares que permite su libre acceso y por tanto, toda forma de uso y la explotación indiscriminada y competitiva de sus recursos.

78 Vitoria, F. de, Relectio de Indis, Madrid, CSIC-CHP, 1967. A esto más extensivamente véase Añaños Meza, M. C., "El título de 'sociedad y comunicación natural' de Francisco de Vitoria. Tras las huellas de su concepto a la luz de la teoría del dominio”, Anuario Mexicano de Derecho Internacional, vol. XII, 2012, pp. 525-596.

79 Deckers, D., Gerechtigkeit und Recht. Eine historisch-kritische Untersuchung der Gerechtigkeitslehre des Francisco deVitoria (1483-1546), Univ.-Verl. Freiburg Schweiz, 1991, pp. 165 y ss. 
Esta revista forma parte del acervo de la Biblioteca Jurídica Virtual del Instituto de Investigaciones Jurídicas de la UNAM

un dominio común de derecho natural, ${ }^{80}$ bajo el cual, todos los hombres eran iguales y libres ${ }^{81}$ y poseían todo en común, teniendo cada persona un derecho a la totalidad de los bienes y estando autorizada a servirse de los bienes disponibles para satisfacer sus necesidades, con la limitación de no dañar a otros. El paso del dominium omnium a la partición de las cosas o divisio rerum, que dio origen a la propiedad privada, se hizo por los hombres por pacto de división (condictum humanum) y tiene a la ocupación como la primera forma de manifestación de la propiedad privada, creándose así un nuevo orden de derecho positivo humano, más exactamente, de ius gentium, que no contradice el derecho natural, sino está justificado con los argumentos aristotélico-tomistas de utilidad y convivencia pacífica. Mas aún después de la divisio rerum, el estado natural no ha sido abolido del todo en Vitoria, por tanto, el dominium omnium natural de cada persona sigue siendo válido, y gracias a él, siguen siendo todos los hombres libres e iguales por derecho natural; el mismo que cobra toda validez en los derechos de caza, pesca y provisión de leña, que sólo deben ser limitados por razones justificables, y cuando alguien pierde sus bienes o se encuentra en estado de extrema necesidad, ${ }^{82}$ abriendo paso a un derecho natural del necesitado de tomar lo necesario para cubrir sus necesidades.

\section{Los bienes comunes como fundamento del dominio español en el nuevo mundo}

Gracias a su amplia concepción de dominio y a su teoría del origen del dominio, Vitoria puede resolver el problema de la legalidad o legitimidad del dominio español en el nuevo mundo. Con base en ellas, sostiene

\footnotetext{
${ }^{80}$ "A principio mundi omnia erant communia", II-II q. 62, 1. n. 9, Vitoria, F. de, De Iustitia, Madrid, Beltrán de Heredia, T. I, 1934.

81 “...omnes homines de jure naturali erant aequales; nullus erat princeps de jure natuali”, II-II q. 62 a. 1 n. 21; adquiriendo la omnia communia un carácter normativo, de derecho natural no preceptivo, sino concesivo, siendo posible apartarse de él por derecho humano.

82 "In extrema necessitate omnia sunt communia" II-II q.62 a.5; n. 15; situación condicionada a que el necesitado esté amenazado de muerte, sin ayuda, y tome lo necesario de quienes tienen en abundancia, véase Deckers, op. cit., pp. 212 y ss.
} 
que el hombre del nuevo mundo poseía un dominio íntegro - público y privado_- que sólo lo pierde por determinadas razones, siendo una de ellas, y la más importante desde el punto de vista jurídico, el título de "sociedad y comunicación natural" o conocido corrientemente como ius communicationis, que hace, a la vez, de primer argumento o título legítimo de una serie de otros siete que le siguen.

El “título de sociedad y comunicación natural” es en Vitoria un principio fundamental del derecho de gentes natural ${ }^{83}$ que porta como elemento esencial la idea de los bienes comunes ${ }^{84}$ y en virtud del cual debe organizarse la comunidad mundial (totus orbis). Por ser un principio de derecho natural, tiene carácter universal y es, por tanto, válido para todos los hombres, independientemente de su pertenencia nacional o cultural. El mismo es también necesario para la humanidad, exigiendo por derecho natural principios de sociabilidad natural que están contenidos en las relaciones de amistad, solidaridad, reciprocidad, hospitalidad, cor tesía, humanidad y comunicación o participación efectiva. Es así que los derechos derivables de este principio fundamental van a tener carácter imperativo u obligatorio, y van a ser causa justificante de intervención o guerra justa en caso del no acatamiento o de la violación de alguno de ellos. Los mismos son: el ius peregrinandi et degendi, el ius negotiandi y el derecho de comunicación y participación de bienes comunes, que también hacen de componentes esenciales. Su ejercicio está sujeto a la condición de que no debe ejercitarse con daño o detrimento de los demás o con agresión a la vida pacífica, y sus titulares no sólo son los pueblos cristianos, sino también otros grupos culturales, pueblos o naciones, a quienes Vitoria les reconoce en principio una subjetividad internacional.

Tanto el ius peregrinandi y ius degendi o libertad de los extranjeros de transitar, inmigrar y residir en las tierras extranjeras, como el ius nego-

\footnotetext{
${ }^{83}$ Vitoria, F. de, op. cit., I 3, I, pp. 77 y ss. Más detalladamente véase Añaños Meza, M.C., op. cit., pp. 573 y ss. El mismo se basa en un ius gentium romano o "ius inter gentes" de la linea de Gayo, que se confundía con el derecho natural, y venía complementado con un ius gentium positivo, también de fuente romana. El dominium abarcaba tanto el derecho natural como el ius gentium positivo y los vinculaba.

${ }^{84}$ Inferible de la voz "comunicación" en su sentido de "poner en común” o "compartir"; de su fuente conceptual en el principio de la communitatis et societatis humanae o doctrina de los bienes comunes de Cicerón, y en los componentes integrantes de este principio, Añaños Meza, M. C., op. cit., pp. 573 y ss.
} 
Esta revista forma parte del acervo de la Biblioteca Jurídica Virtual del Instituto de Investigaciones Jurídicas de la UNAM

tiandi o derecho de comercio, están dados por una serie de libertades que a la vez imponen un buen número de obligaciones como la de no prohibir el ejercicio de tales libertades sin causa justificable, el buen tratamiento a los extranjeros, no impedir la comunicación y el trato entre los hombres, no desterrar sin causa justificable, no estorbar el comercio y la comunicación entre los hombres, recibir a los huéspedes, no expulsar a los extranjeros y no prohibir el bienestar de los españoles. ${ }^{85}$ Mas son ante todo el ius peregrinandi y ius degendi los que van a contener también la doctrina de los bienes comunes al exigir expresamente el cumplimiento de la obligación de no vedar el uso de los bienes comunes.

El tercer componente de este principio fundamental es el derecho de comunicación y participación de bienes comunes, que está más estrechamente ligado a la doctrina de los bienes comunes, y por consiguiente, al derecho natural. El mismo se aprecia en la siguiente cita: "Si hay entre los bárbaros cosas comunes a los nacionales y a los extranjeros, no es lícito que los bárbaros prohiban a los españoles la comunicación y participación de esas cosas" ${ }^{86}$ Se trata aquí de una norma que presupone la existencia real de bienes comunes en el nuevo mundo y de un derecho de compartir y participar en ellos, cuyo ejercicio está condicionado a la ausencia de daño o perjuicio; siendo titulares tanto españoles como amerindios, quienes a la vez tienen la obligación de garantizar su libre acceso para todo el que quiera aprovecharlos. Si Vitoria señaló directamente a los amerindios como obligados de compartir y no prohibir su uso, e incluso, de no impedir la adquisición de propiedad de cosas sin dueño, fue por la simple razón de que eran los españoles los más activos en hacer uso de los bienes comunes.

Tomando como base el derecho romano, son en Vitoria bienes comunes a los amerindios y españoles el aire, el agua corriente, los ríos, el mar, los puentes ${ }^{87}$ y también las “tierras”, sin indicar aquí a qué tierras se refiere. Por tanto, estas cosas y "tierras" comunes están abiertas al uso de todos, y los productos valiosos que se extraen de ellas, como oro o plata, pueden ser objeto de apropiación por los españoles si los amerindios no las extraen o explotan. Es de tenerse en cuenta que el derecho de

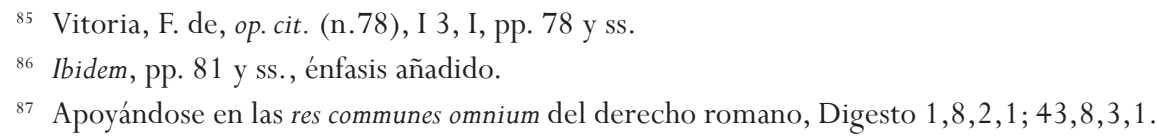


comunicación y participación de bienes comunes sólo considera como "bienes comunes" las áreas del nuevo mundo que han sido descubiertas por los españoles y que a la vez están sujetas al dominio de los amerindios por ocupación original. Gracias al título de descubrimiento o ius inventionis, válido en Vitoria, los españoles no adquieren un derecho de propiedad sobre tales áreas descubiertas, ya que son de propiedad de los amerindios, sino simplemente un derecho de uso sobre ellas, estando tanto españoles como amerindios en la obligación de compartir su uso y aprovechamiento económico, y por tanto, garantizar su acceso libre. En otras palabras, en los bienes comunes Vitoria reconoció a los amerindios un derecho de dominio de sus tierras y recursos, pero también a los españoles un derecho de uso de esas tierras y recursos por descubrimiento o ius inventionis.

Por otro lado, basándose igualmente en el derecho romano, Vitoria supo distinguir muy bien entre bienes comunes y cosas sin dueño o res nullius en el nuevo mundo. Estas últimas eran áreas o espacios geográficos que no estaban poblados o habitados por amerindios y se encontraban más allá de su poder de ocupación, como fue el caso de muchas regiones deshabitadas del nuevo mundo en el siglo XVI. El dominico reconoció en estas áreas su naturaleza jurídica de res nullius, las que podían ser directamente objeto de apropiación y estaban regidas por el derecho de primera ocupación ${ }^{88}$ para la obtención de su propiedad y en virtud del ius gentium positivum. ${ }^{89}$ Es aquí, entonces, donde Vitoria admite la adquisición originaria de propiedad privada y pública de estos bienes y es el punto donde abandona el campo del ius gentium natural para entrar al del derecho de gentes positivo.

Sin embargo, las consecuencias del no cumplimiento de las obligaciones emanadas del principio de "sociedad y comunicación natural" o el impedimento del ejercicio de las libertades derivadas de él, fueron graves, y radicaban en una "transgresión o violación" de tales derechos equivalente a una iniuria y ésta es causa justificable de guerra, la que

${ }^{88}$ Vitoria, F. de, op. cit., p. 5. Conocida en el derecho romano como forma originaria de adquisición del dominio.

89 Vitoria entendió la ocupación como un instituto del ius gentium positivo, junto a la inviolabilidad de los embajadores, el uso común de los mares, la esclavitud por cautiverio y la no expulsión de los extranjeros. 
llevaría a la pérdida del dominio por parte de los amerindios y a la adquisición de dominio legítimo sobre las tierras del nuevo mundo y sus hombres por parte de los españoles. La guerra justa permitía un derecho sobre las res hostiles u ocupación y apropiación de los bienes del enemigo vencido y del enemigo mismo, concepción ésta básicamente punible de la guerra justa, que era la postura tradicional en el tiempo de Vitoria.

El derecho internacional público positivo y la doctrina iusinternacional de siglos posteriores a Vitoria no recepcionan su doctrina de los bienes comunes — quizá por lo complicado de su construcción teórica-, a pesar de la intensificación de las prácticas colonizadoras por potencias europeas que sucedieron a España; en cambio, la doctrina de las res nullius constituyó el título de dominio sobre las tierras de África, Asia, Oceanía y donde habitaban culturas autóctonas, ya que a éstas no se les reconoció subjetividad internacional alguna, debido principalmente al sistema interestatal del derecho internacional público. El principio de las res nullius cobró, entonces, fuerza en los siglos posteriores a Vitoria.

\section{CONCLUSIÓN}

Es de saludarse el redescubrimiento de los bienes comunes en los estudios hechos desde las ciencias económicas y en la presencia de los commons intangibles en tiempos de alta coyuntura del turbo-capitalismo. Gracias a los aportes de la ciencia económica sobre recursos de uso común, se conoce que éstos pueden ser exitosamente manejados por el hombre de forma colectiva mediante un régimen autorregulativo eficiente, justo y sostenible; que tienen como factores determinantes de su éxito a cualidades sociales del hombre como la comunicación, participación, confianza, reciprocidad, solidaridad, cooperación, etcétera, y que también enfrentan problemas de sobreuso y del polizón que pueden conducir a su fracaso.

En el sistema internacional, los únicos recursos globales no sometidos a la soberanía de los Estados que alcanzaron regulación internacional fueron los fondos marinos y el espacio ultraterrestre mediante el ré- 
gimen del patrimonio común de la humanidad, el cual intentó superar el concepto histórico de los "bienes comunes" como espacios de acceso abiertos carentes de regulación. El mecanismo más avanzado, el de los fondos marinos, fracasó sobre todo por la regulación deficiente de sus recursos y carente de su uso económico privado, por la no ejecución de lo regulado y por el vaciamiento del principio del $\mathrm{PCH}$ en el Acuerdo de Implementación, que han forzado el regreso del principio de la libertad de los mares y la amplia vigencia del estatus de res nullius en sus recursos. Similarmente, en el espacio ultraterrestre y sus cuerpos celestes, cuya regulación es aún más rala, prima el principio de la libertad espacial. Estando los principios de la libertad de los mares y libertad espacial en clara contradicción con el principio del $\mathrm{PCH}$, estos espacios no son "bienes comunes" en el sentido de la propuesta original del $\mathrm{PCH}$, ni menos en el de Ostrom, sino siguen siendo bienes "libres" e incluso res nullius sujetos al lema de first come first served; estando expuestos a las leyes del libre mercado y privatización, y a su cercamiento o extinción. Ello demuestra la inexistencia de la cooperación en la sociedad internacional, por no existir un interés común global de su acceso y manejo colectivo para el bien de la humanidad, ni cierto grado de homogeneidad y equilibrio entre sus miembros, conduciendo esta situación a la conducta egoísta del gorrón o polizón que privatiza las ganancias de su acceso y uso, y socializa sus costos en la humanidad, desenvocando irremediablemente en la "tragedia de los communes", la que se hace aún más grave y apremiante en el presente, con la intensificación de las actividades privadas en estos espacios.

Sin embargo, el régimen de bienes comunes no tiene otra alternativa ética mejor; ello sobre todo tratándose de recursos globales que por su naturaleza son comunes, y cuyo reconocimiento como tales es declarativo, no constitutivo. Se hace pues, necesaria una decisión firme en pensarlos seriamente como "bienes comunes" y recuperar el principio del $\mathrm{PCH}$ en los fondos marinos y espacio ultraterrestre, teniendo en cuenta las propuestas de sus propulsores de los años sesenta y los aportes de Ostrom y colegas. Para ello, son imprescindibles una mayor atención sobre los problemas de estos recursos y estudios sobre ellos. Asimismo, a nivel político, los países del tercer mundo y en vías de desarrollo están llamados a renovar esta idea; lo que requiere también que 
Esta revista forma parte del acervo de la Biblioteca Jurídica Virtual del Instituto de Investigaciones Jurídicas de la UNAM

ellos mismos trabajen por su independencia y comiencen a cooperar entre sí para defenderla con una sola voz en los foros internacionales, en forma eficiente como defienden sus intereses los Estados altamente industrializados. Paralelamente, se requerirá de la participación activa de la sociedad mundial en foros internacionales, organizada en individuos, comunidades, organismos no estatales, etcétera, para exigir un poder de decisión directa sobre asuntos sustanciales que atañen a estos bienes, procedimiento éste que amenguaría en algo las relaciones de dependencia entre los Estados que bloquea la defensa de los intereses de Estados dependientes, y las tendencias de privatización y comercialización. Cada uno de nosotros, individuos, como personificación de la humanidad, estamos llamados a velar por estos bienes y estamos en la condición de reclamarlos con todas sus consecuencias, esto es, exigiendo una reglamentación adecuada que incluya la imposición de cargas o gravámenes por toda clase de beneficio comercial y privado, cuyo monto sea distribuido entre todos los Estados por igual y, según el caso, vaya, por ejemplo, a un fondo social de cada Estado para el bien de sus habitantes más necesitados o socialmente desventajados, o se invierta en la educación de éstos.

Dando una mirada histórica a la idea de los bienes comunes, se encuentra su empleo en el siglo XVI por Francisco de Vitoria como fundamento justificador del dominio español en el nuevo mundo. Al sostener la existencia de bienes comunes en este continente, éstos debieron ser compartidos por españoles y amerindios, siendo el principio universal de "sociedad y comunicación natural" el que exigía su goce común y el goce de las libertades derivadas de él. Mientras en el ius peregrinandi et degendi y ius negotiandi estaban en juego el acceso libre a las tierras del nuevo mundo, en el derecho de comunicación y participación de los bienes comunes, el uso de los recursos naturales del nuevo mundo. La pérdida del dominio de los amerindios sólo podía proceder por guerra justa y después de haber obstruído o impedido el acceso y uso libre de los bienes comunes. Con ello, Vitoria plantea ya en su tiempo los problemas actuales de acceso, uso y explotación de espacios comunes y de sus recursos naturales, aunque con el matiz de que no trató recursos globales como los océanos, sino los espacios y recursos del nuevo mundo, que debe verse bajo el fenómeno del colonialismo. Asimismo, varios 
elementos de su doctrina de los bienes comunes han sido redescubiertos por la ciencia moderna de los bienes comunes y son elementos importantes del régimen del $\mathrm{PCH}$, como los principios de participación, comunicación, sociabilidad, reciprocidad, solidaridad y cooperación; sin embargo, Vitoria descuidó el factor de la equidad, elemento importante para la ciencia moderna de los bienes comunes y el principio del $\mathrm{PCH}$.

Con todo lo expuesto, se puede concluir diciendo que la sociedad internacional está muy lejos de aceptar la idea de los bienes comunes como iniciativa del PCH o como propuesta de acción colectiva. Sólo es posible referirse a su renacimiento como tarea que queda por hacer en el futuro.

\section{BIBLIOGRAFÍA}

ANAND, R. P., "Common Heritage of Mankind: Mutilation of an Ideal”, Indian Journal of International Law, vol. 37, núm. 1, 1997, 1-18.

AÑAÑos MEZA, M.C., "El título de 'sociedad y comunicación natural' de Francisco de Vitoria. Tras las huellas de su concepto a la luz de la teoría del dominio", Anuario Mexicano de Derecho Internacional, vol. XII, 2012.

BARDAHN y DAYTON-JOHNSON, "Unequal Irrigators: Heterogenity and Commons Management in Large Scale Multivariate Research", OsTROM, E. et al. (eds.), The Drama of the Commons, National Academy Press, Wahington DC, 2002.

Benkler, Y., The Wealth of Networks, Yale University Press, 2006.

Boyle, J., "The Second Enclosure Movement and the Construction of the Public Domain”, Law and Contemporary Problems, vol. 66, 2003.

Cloppenburg, J., "Legal Aspects of Space Tourism", en BenkÖ y Schrogl, Space Law: Current Problems and Perspectives for Future Regulation law, Eleven, Utrecht, 2005.

COCCA, A. A., "The Advances in International Law Through the Law of Outer Space", 9 Journal of Space Law, 1981. , Consolidación del derecho espacial, Buenos Aires, Astrea, 1971. 

1970.

DECKERS, D., Gerechtigkeit und Recht. Eine historisch-kritische Untersuchung der Gerechtigkeitslehre des Francisco de Vitoria (1483-1546), Univ.-Verl. Freiburg Schweiz, 1991.

Doyle, S. E., "Issues of Sovereignty and Private Property", en BENKÖ y KOLL (eds.), Luft und Weltraumrecht im 21. Jahrhundert, Carl Heymanns, Köln 2001.

French, G. A., Der Tiefseebergbau, Carl Heymanns Verlag KG, Köln 1990.

Hardin, G., "Extensions of 'The Tragedy of the Commons'”, Science, 280 (1998), 682-683.

, "The Tragedy of the Commons", Science, nueva serie, vol. 162, núm. 3859, 1968.

HELFRICH, S. et al., Gemeingüter - Wohlstand durch Teilen, Berlín, Report Heinrich Böll Stiftung.

Helfrich y STEIN, “Was sind Gemeingüter?”, APuZ 28-30, 2011.

Hobe, S., "Outer Space as the province of mankind - An Assessment of 40 years of development", IISL/AIAA, Procedings of the fifth colloquium on the law of outer space, 24-28 sept. 2007, India.

Grotius, H., The Freedom of the Sea, Londres, Oxford University Press, 1916.

Keohane y Ostrom (eds.), Local Commons and Global Interdependence, Londres, Sage Publications, 1995.

Kewenig, W.A., "Common Heritage of Mankind-Politischer Slogan oder völkerrechtlicher Schlüsselbegriff?”, en VON MüNCH, I. (ed.), Staatsrecht-Völkerrecht-Europarecht, Berlín, Gruyter, 1981.

KimminiCH, O., Einführung in dasVölkerrecht, 6. Aufl., UTB Franke, Tübingen 1997.

KISS, A., "The Common Heritage of Mankind: Utopia or Reality?", 40 Int'l J., 1984-1985.

KRIES, W., "Legal Aspects of the Growing Military Uses of Outer Space”, en Benkö y SCHROgL, Space Law: Current Problems and Perspectives for Future Regulation, Eleven, Utrecht, 2005. 
MolenaAr, E. y OUde, A. (eds.), The International Legal Regime of Areas Beyond National Jurisdiction: Current and Future Developments, Leiden, Martinus Nijhoff, 2010.

Olson, M., La lógica de la acción colectiva: bienes públicos y la teoría de grupos, México, Limusa, 1992.

Ostrom, E. et al. (eds.), The Drama of the Commons, Washington DC, National Academy Press, 2002.

Ostrom, E., El gobierno de los bienes comunes, México, Fondo de Cultura Económica, 2000.

Riedel y Rothen (eds.), The Human Right toWater, Berlín, Berliner Wissenschafts-Verlag, 2006.

SenghaAs, D., "La gobernanza mundial y el derecho mundial en un mundo fragmentado", Jueces para la Democracia, julio de 2010.

ShragA, D., "The Common Heritage of Mankind: The Concept and its Application”, Annales D’Études Internationales, vol. 15, 1986.

SoHn, L. B., "Explotación del Lecho Marino fuera de la Plataforma Continental”, Revista Integración, 1968.

Steinacker, K., The Legal Principles of the Common Heritage of Mankind and DeepSea-Bed Mining aoutside the U.N. Convention of the Law of the Sea, Berlin, Wisseschafticher Autoren-Verlag, 1985.

Vitoria, F. de, De Iustitia, ed. Beltrán de Heredia, t. I, Madrid, 1934.

- Relectio de Indis, Madrid, CSIC-CHP, 1967.

Waltz, K., Theory of International Politics, Addison-Wesley P.C., 1979.

WisKOw, J.-H., Zur Verfassung der Meere, Köln, Institut der Universität zu Köln, 2002.

Witschen, D., Christliche Ethik der Menschenrechte: Systematische Studien, Hamburg, Litt, 2002.

Wolfrum, R., "Common Heritage of Mankind", Max Planck Encyclopedia of Public Internatrional Law, Oxford University Press, 2012. 1983.

1984.

WOLTER, D., Grundlagen “Gemeinsamer Sicherheit” im Weltraum nach universellem Völkerrecht, Berlín, Duncker \& Humblot, 2003. 